\title{
Eficiência Adaptativa nos Mercados Futuros Agropecuários Brasileiros*
}

\author{
Marcos Aurelio Rodrigues ${ }^{\dagger}$ \\ João Gomes Martines Filho ${ }^{\ddagger}$
}

\author{
Sumário: 1. Introdução; 2. Eficiência dos mercados; 3. Metodologia; 4. A hipótese adaptativa dos \\ mercados agropecuários brasileiros; 5 . Considerações finais. \\ Palavras-chave: Razão de Variância, Eficiência de Mercado, Commodities. \\ Códigos JEL: G14, Q14.
}

Objetivou-se neste estudo analisar a eficiência dos mercados futuros agropecuários brasileiros, sob a hipótese adaptativa de mercado. Utilizando propostas recentes à não linearidade e razão de variância, encontrou-se que as elevadas rejeições à hipótese de diferença martingal se encontram nos mercados em que as intervenções governamentais se fazem presentes: milho e etanol. Nos mercados de café, boi gordo e soja ocorreram menores rejeições à hipótese martingal e, portanto, houve maior eficiência informacional. Essas evidências - consistentes com a hipótese adaptativa dos mercados — justificam operações de hedge dinâmicas, bem como a gerência de carteiras de investimentos de forma ativa.

This study aims to analyze the degree of efficiency of Brazilian agricultural future markets, under the adaptive market hypothesis. Through recent developments for Nonlinearity and Variance Ratio tests, it has been shown that the rejections to the martingale difference hypothesis at high levels are found in markets that governmental intervention is recurrent-i.e., corn and ethanol. Concerning coffee, live cattle, and soybeans markets, weaker rejections to the martingale hypothesis indicate a higher level of informational efficiency in these three markets when compared to both corn and ethanol future markets. These evidences - consistent with the adaptive market hypothesis - justify dynamic hedge operations, as well as an active management of investment portfolios in such markets.

\footnotetext{
*Os autores agradecem aos comentários e sugestões do editor, do parecerista anônimo, assim como de Alexandre Florindo Alves, Daniel Henrique Dario Capitani, José Cesar Cruz Júnior, Juan Carlos Escanciano e Paulo Fernando Cidade de Araújo.

${ }^{\dagger}$ Tribunal de Justiça do Estado do Paraná (TJPR). Email: rodriguesmarcosaurelio@gmail . com.

†Escola Superior de Agricultura "Luiz de Queiroz" (ESALQ), Universidade de São Paulo (USP). Av. Pádua Dias, 11, Piracicaba, SP, Brasil. CEP 13418-900.
} 


\section{INTRODUÇÃO}

As políticas de preços agropecuários no Brasil foram historicamente marcadas por intervenções nos mercados. Até a década de 1980, o uso de instrumentos que minimizam as flutuações de preços recebidos pelos produtores rurais, aliado às intervenções diretas nos mercados agropecuários, dificultavam o desenvolvimento dos derivativos agropecuários brasileiros. Diante das crises fiscais do Governo Federal, foram tomadas medidas de redução de gastos públicos e houve menor intervenção nesses mercados, o que propiciou um ambiente favorável para que os derivativos agropecuários pudessem desenvolver-se.

A evolução dos mercados futuros agropecuários foi acompanhada pela criação de novos contratos e modificações contratuais depois de seu lançamento, desde a criação Bolsa Mercantil \& de Futuros (BM\&F) - em 1986, até a sua atual e recente denominação — Bolsa de Valores, Mercadorias e Futuros (BM\&FBOVESPA). Teve início com contrato futuro de café e posterior lançamento de alguns contratos, dentre eles: de boi gordo, milho, soja e etanol. Diversas modificações contratuais foram executadas pela Bolsa brasileira com o intuito de melhorar o funcionamento desses mercados: adequar-se às demandas dos agentes, aumentar a visibilidade dos contratos e, por conseguinte, a eficiência dos mesmos.

Um mercado no qual os preços sempre refletem integralmente as informações disponíveis é considerado eficiente; em particular, sob a hipótese fraca ${ }^{1}$ de eficiência, os preços dos ativos refletem toda informação contida nos preços históricos dos mercados (Fama, 1970). A eficiência de mercado não é uma condição "tudo ou nada", mas uma característica que varia continuamente no tempo e entre mercados (Lo, 2005).

De acordo com Timmermann \& Granger (2004), apesar de o comportamento dos participantes dos mercados propiciar retornos condizentes com a hipótese de eficiência, é necessário considerar, detectar e utilizar quaisquer previsibilidades temporárias, que podem aparecer e/ou desaparecer rapidamente. Devido às características levantadas por Lo (2004), essas oportunidades podem desaparecer depois de exploradas ou novas oportunidades serem criadas nos mercados. No que se refere à eficiência adaptativa dos mercados, estudados por Lo (2004), as características suscetíveis a mudanças são: nas condições de mercado, nas instituições, nas tecnologias de informação e/ou nas preferências dos participantes. Note que essas mudanças costumam ocorrer nos mercados brasileiros de commodities agropecuárias. Com base nesses argumentos, novas percepções podem ser obtidas sobre a eficiência dos mercados, pois é razoável esperar que a eficiência de mercado também evolua com o tempo.

O objetivo geral deste estudo é analisar a eficiência dos mercados futuros agropecuários no Brasil, sob a hipótese adaptativa dos mesmos. De modo especifico, pretende-se verificar se os retornos diários dos contratos futuros obedecem a uma sequência de diferenças martingal. Esta pesquisa se diferencia em relação à literatura sobre a eficiência dos mercados agropecuários por utilizar propostas mais recentes — relacionadas à não linearidade e razão de variância, bem como por investigar a eficiência adaptativa dos mercados.

Esta pesquisa tem a seguinte estrutura, além desta introdução: na segunda parte, discussão teórica e evidências empíricas sobre a hipótese adaptativa de mercado, bem como suas implicações; na terceira parte, descrição da metodologia utilizada para o teste de sequência de diferenças martingal; na quarta parte, análise dos resultados obtidos; e, finalmente, as considerações finais.

\section{EFICIÊNCIA DOS MERCADOS}

Segundo Lo (2012), a hipótese de eficiência de mercado serve como boa aproximação da realidade sob condições econômicas estáveis, estacionárias e previsíveis. No entanto, ele ressalta que em ambientes mais dinâmicos e estocásticos, essa hipótese se torna menos plausível. $\mathrm{O}$ arcabouço sugerido em Lo (2004) e Lo (2005), denominado de hipótese adaptativa de mercado, proporciona consistência sob conjunturas econômicas de incerteza e turbulência, e pode ser visto como uma nova versão da hipótese de eficiência de mercado.

\footnotetext{
${ }^{1}$ As demais hipóteses podem ser vistas em Fama (1970).
} 
A hipótese adaptativa de mercado deriva de princípios evolucionários e seus componentes consistem das seguintes ideias: a) os indivíduos agem por interesse próprio; b) os indivíduos cometem erros; c) os indivíduos aprendem e adaptam-se; d) a concorrência gera adaptação e inovação; e) a seleção natural forma o mercado; e f) a evolução determina as dinâmicas dos mercados (Lo, 2004, 2005).

Exemplificando o ciclo evolutivo do mercado, Lo (2005) destaca que as oportunidades de lucro assemelham-se às disponibilidades de recursos naturais — quanto mais recursos, menos feroz a concorrência. Com aumento na concorrência, seja pela diminuição das oportunidades ou pelo aumento dos agentes, as oportunidades se esgotam, o que, eventualmente, levaria ao declínio da população, diminuindo o nível de concorrência e se inicia o ciclo novamente. Mas, conforme o autor, esse ciclo pode convergir para situações de canto, ocorrendo a eliminação de certos agentes. Portanto, essa hipótese implica que a eficiência dos mercados agropecuários depende de suas características evolutivas e da adaptabilidade de seus participantes às constantes mudanças inerentes a esses mercados.

Assim, inferências sobre a eficiência dos mercados agropecuários possuem importantes implicações para comercialização, transmissão de informações, políticas governamentais, hedge e especulação. Em relação à comercialização, segundo Garcia, Hudson \& Waller (1988), produtores e empresas utilizam informações geradas nos mercados futuros em suas decisões de produção, comercialização e estocagem. Entretanto, os agentes do agronegócio podem tomar decisões errôneas, sujeitas a informações incompletas contidas nos preços passados, se os mercados não forem eficientes. Se os preços nesses mercados futuros não refletirem as expectativas de oferta e demanda dos mercados à vista, podem resultar em alocação ineficiente de recursos e, por conseguinte, numa possível redução do excedente econômico (Garcia et al., 1988).

A transmissão de informações dos preços, à vista e futuros, para os agentes do agronegócio, decorre da visão desses agentes sobre os preços dos contratos futuros e prevalecentes no mercado à vista. Essa atribuição de sinalização, formação e descoberta de preços é considerada adequada se refletir rapidamente todas as informações recebidas pelos seus participantes. Então, quando o mercado é eficiente, possibilita eficiência alocativa, redução de imprecisão nas decisões dos agentes e dos custos das informações (Arbex \& Carvalho, 1999; Garcia, Leuthold \& Egelkraut, 2008). Assim sendo, as informações contidas nos preços são preponderantes para o funcionamento adequado dos mercados agropecuários no Brasil.

Segundo Sabuhoro \& Larue (1997), reduções nos gastos governamentais em políticas de subvenção propiciam aos agentes considerar a gestão de risco de preços em mercados futuros. Os mercados de commodities no Brasil passaram por medidas de redução de gastos públicos na agropecuária e redução do grau de intervenção governamental. Essas medidas implicaram redução de subsídios, a exemplo das atuais políticas de garantia de preços mínimos. Na década de 1990, o Estado iniciou um amplo processo de desregulamentação da economia, e, em particular, em várias atividades vinculadas à agropecuária. A falta de recursos orçamentários, durante essa década e dos anos 2000 , levou à redução da efetividade das políticas de preços do Governo Federal (Bacha, 2012). No entanto, os agentes podem ser relutantes ao uso dos mercados de derivativos como alternativa às políticas governamentais, pois em mercados não eficientes há custos de transação adicionais ao hedge (Sabuhoro \& Larue, 1997).

As commodities negociadas na BM\&FBOVESPA apresentam grande volatilidade dos preços subjacentes à vista, o que justifica o uso de contratos futuros para hedge. Capitani, Mattos \& Martines (2012) apontaram para desvio padrão superior no mercado de café arábica seguido por boi gordo, enquanto os Valores em Risco (VaR) de todas as commodities agropecuárias negociadas nessa Bolsa possuem comportamentos semelhantes entre si. Segundo Marques, Mello \& Martines (2008) e Alves, Duarte \& Lima (2008), diante da exposição ao risco, os agentes montam operações de hedge com derivativos que lhes permitem a efetiva administração de risco de preços na BM\&FBOVESPA, desde que o mercado seja eficiente, tornando as relações de mercado mais estáveis. Ao se falar que o mercado se tornou eficiente ou melhorou sua eficiência, afirma-se que melhorou a possibilidade de todos os participantes fazerem um hedge adequado às suas necessidades (Frick \& Campos, 1996).

Segundo Chen, Lee \& Shrestha (2003), uma das estratégias de hedge mais utilizadas se baseia na minimização da variância do portfólio "hedgeado" sob o arcabouço de média variância, na qual a solução 
é a razão ótima de hedge. Como apontado no survey de Chen et al. (2003) e demonstrado em Kroner \& Sultan (1993), essa razão de hedge só será ótima se os preços futuros seguirem um processo martingal. Uma vez que, segundo Samuelson (1965) e Fama (1970), os preços em mercados eficientes devem seguir um processo martingal, essa estratégia de hedge ótima depende da hipótese de eficiência de mercado.

Além dos agentes que fazem hedge de suas posições em risco nos mercados futuros agropecuários negociados na BM\&FBOVESPA, especuladores, administradoras de fundos de investimentos e de pensão têm sido atraídos devido às possibilidades de ganhos nesses mercados (Marques et al., 2008). Para esses autores, os especuladores dos mercados de derivativos agropecuários fazem uso intensivo de informações contidas nos preços passados e geralmente utilizam a análise técnica (grafista) para tomar decisões. Mas, conforme ressaltam Torres, Bonomo \& Fernandes (2002), em mercados eficientes, estratégias de trading baseadas em informações passadas não gerariam lucros extraordinários. Uma possível confirmação da hipótese martingal nesses mercados implicaria que técnicas de análise gráfica e os modelos econométricos de previsão de preços de ativos consistiriam em esforço inútil na busca de lucros extraordinários. Essas implicações são consequências da eficiência da forma fraca do mercado (Torres et al., 2002).

\subsection{Síntese da literatura empírica}

A literatura empírica pode ser categorizada segundo a metodologia utilizada para analisar a hipótese de eficiência de mercado. De acordo com Escanciano \& Lobato (2009b), essa hipótese, nas análises dos mercados, comumente se referencia às hipóteses de sequência de diferenças martingal (sob não predicabilidade linear ou não linear dos retornos passados) e de passeio aleatório (sob não predicabilidade linear dos retornos passados). Segundo Charles \& Darné (2009), essas hipóteses oferecem o arcabouço testável quanto à eficiência fraca de mercado proposta por Fama (1970) e, consequentemente, à não predicabilidade dos mercados.

Os estudos em mercados agropecuários foram revistos nos surveys de Garcia et al. (1988); Garcia \& Leuthold (2004) e em mercados financeiros no survey de Lim \& Brooks (2011). Nesses surveys, o comportamento martingal/passeio aleatório às séries temporais, assim como o não enviesamento dos mercados futuros aos mercados à vista, foi observado por meio de testes estatísticos como: correlações seriais, raiz unitária, cointegração e dependência serial não linear.

Em relação aos mercados agropecuários brasileiros (Tabela 1), a literatura evoluiu de forma semelhante à demonstrada internacionalmente por Garcia et al. (1988) e Garcia \& Leuthold (2004), entretanto com certa defasagem temporal. Nota-se que, tanto na literatura nacional quanto na revista por esses au-

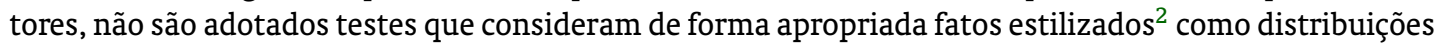
não normais e não linearidade das séries.

Frick \& Campos (1996), Saboya \& Bacchi (1999), Bressan \& Leite (2001) e Abitante (2008) analisaram os contratos de diferentes vencimentos de forma separada, sem rolagem com os contratos subsequentes, como os demais autores. Encontraram evidências favoráveis e desfavoráveis à eficiência de mercado. Apesar de não explicitarem em seus estudos, são evidências de que esses mercados podem variar entre períodos de eficiência e não eficiência no tempo. Notam-se evidências discrepantes relacionadas aos mesmos ativos, entre mercados e dependentes dos métodos e dos dados utilizados, conforme apontado por Garcia et al. (1988). O único estudo que analisou a eficiência nos mercados agropecuários à vista foi o de Righi \& Ceretta (2011), com resultados desfavoráveis à eficiência.

Conforme os surveys de Garcia et al. (1988) e Garcia \& Leuthold (2004), nos estudos iniciais em mercados agropecuários, houve predominância no uso de correlogramas e correlações seriais. Com o advento de testes de raiz unitária e cointegração, passaram a utilizá-los para as inferências da hipótese fraca de eficiência. Mas as estatísticas portmanteau $Q$ (Box-Pierce e Lijung-Box) e de raiz unitária estatística (Dickey-Fuller) podem gerar resultados errôneos para verificar um passeio aleatório (Hakkio, 1986). Em

\footnotetext{
${ }^{2}$ Ver, por exemplo, Cont (2001), para evidências nos mercados internacionais, e Lima, Góis \& Ulises (2007) no mercado brasileiro.
} 
Tabela 1. Estudos empíricos sobre a eficiência dos ativos agropecuários brasileiros.

\begin{tabular}{|c|c|c|c|c|}
\hline Autores & Ativos & Metodologia & Período $^{\mathfrak{a}}$ & $\begin{array}{l}\text { Evidência } \\
\text { à eficiência }\end{array}$ \\
\hline Frick \& Campos (1996) & Boi gordo & Correlação serial & 1991-96 & mista \\
\hline Saboya \& Bacchi (1999) & $\begin{array}{l}\text { Açúcar, algodão, boi gordo, } \\
\text { café, milho e soja }\end{array}$ & $\begin{array}{l}\text { Raiz unitária } \\
\text { e correlação serial }\end{array}$ & 1996-99 & mista \\
\hline Arbex \& Carvalho (1999) & Café & Cointegração & 1992-98 & favorável \\
\hline Bressan \& Leite (2001) & Café & Correlação serial & $1992-98$ & mista \\
\hline Cruz \& Silveira (2007) & Café & $\begin{array}{l}\text { Raiz unitária } \\
\text { e cointegração }\end{array}$ & $2002-06$ & favorável \\
\hline Alves et al. (2008) & Etanol & Cointegração & $2000-06$ & desfavorável \\
\hline Abitante (2008) & Boi gordo e soja & Cointegração & 2005 & mista \\
\hline $\begin{array}{l}\text { Moraes, Lima \& de } \\
\text { Souza Melo (2009) }\end{array}$ & Boi gordo & Cointegração & $2000-04$ & favorável \\
\hline Fraga \& Silva (2011) & Soja & Cointegração & $2007-08$ & desfavorável \\
\hline Righi \& Ceretta (2011) & Soja, algodão, café e milho & Razão de variância & $2006-10$ & desfavorável \\
\hline $\begin{array}{l}\text { Menegario, Paiva, Souza, } \\
\text { Martines \& Marques (2014) }\end{array}$ & Café & Cointegração & $2008-10$ & favorável \\
\hline
\end{tabular}

a denota o uso de séries diárias.

simulações de Monte Carlo, demonstrou-se que esses testes têm baixo poder relativo, pois não distinguem entre um passeio aleatório e algo próximo a um passeio aleatório. Posterior às noções de cointegração, houve predomínio de estudos relacionando o possível enviesamento entre os mercados à vista e futuros, mas não inferências sobre predicabilidade, com base nos retornos passados, conforme sugerem Samuelson (1965), Fama (1970), Timmermann \& Granger (2004) e Lo (2005).

Os estudos agropecuários subsequentes à revisão de Garcia \& Leuthold (2004) fizeram uso desse possível enviesamento, a exemplo de Wang \& Ke (2005), Carter \& Mohapatra (2008), entre outros, para verificar de forma indireta a hipótese de eficiência fraca de mercado. Exceção foi o estudo de Hussein (2011) que utilizou os testes de razão de variância (Lo-MacKinlay) e não linearidade (Brock-DechertScheinkman).

De acordo com Escanciano \& Lobato (2009b), mensura-se a dependência de forma linear devido à suposição de que as séries seguem distribuições normais. Porém, há como fato estilizado que as séries possuem caudas pesadas, logo não têm comportamento normal (Cont, 2001). Assim, segundo Escanciano \& Lobato (2009b), a literatura econométrica seguiu duas abordagens alternativas. A primeira com foco em dar robustez às mensurações lineares para que permitam dependências não lineares, como em Escanciano \& Lobato (2009a) e Kim (2009). Essa abordagem tem como vantagem a simplicidade, pois segue distribuições assintóticas-padrão. A segunda abordagem considera mensurações para as dependências não lineares, como em Escanciano \& Velasco (2006) e Domínguez \& Lobato (2003). Sua vantagem é o poder dos testes, mas requer distribuições assintóticas não triviais. Essa desvantagem pode ser superada por procedimentos de bootstrap, sendo o wild bootstrap o mais relevante (Escanciano \& Lobato, 2009b). Recentemente, essas duas abordagens foram aplicadas por Charles, Darné \& Kim (2012) e Lim, Luo \& Kim (2013) no contexto de mercados acionários e cambiais, respectivamente, além de Dourado \& Tabak (2013) que as aplicaram para o mercado acionário brasileiro.

Vale destacar que, além dessa literatura, cujo foco está na previsibilidade dos retornos, outra categoria de estudos sobre eficiência de mercado possui como enfoque a análise da lucratividade de regras de análise técnica. As possíveis arbitragens advindas dessas regras foram analisadas, recentemente, por meio da classe de testes de realidade utilizando bootstrap, a exemplo de White (2000). Segundo Gar- 
cia \& Leuthold (2004), ao ser procedida a análise informacional sob esse enfoque, é relevante verificar, além da significância estatística consistente com os retornos ajustados ao risco, se os resultados passam pelo teste de realidade para data snooping. ${ }^{3}$ Tal literatura foi revista por Park \& Irwin (2007), sendo amplamente explorada nos mercados financeiros e, em menor quantidade, em ativos agropecuários. Ao ser evidenciada lucratividade dessas regras com controle aos possíveis efeitos de data snooping, evidencia-se possíveis arbitragens nos mercados financeiros e agropecuários, e, consequentemente, sobre a eficiência de mercado.

Lim \& Brooks (2011) demonstraram que a literatura em ativos financeiros evoluiu em direção a testes mais robustos, que consideram a não linearidade e a possibilidade de eficiência relativa. Essa possibilidade foi verificada em estudos com adoção de janelamento móvel de subamostras, que, além de permitir a análise da eficiência relativa, provê uma forma de hierarquizar a eficiência entre mercados.

Ao comparar a literatura empírica com ativos financeiros e agropecuários, não foram abordados na análise da eficiência dos mercados agropecuários: a) o uso das propostas mais recentes, relacionadas à não linearidade e razão de variância, dispostas em Escanciano \& Lobato (2009b) e Charles \& Darné (2009); e b) a possibilidade de eficiência variante no tempo, sugerida por Lo $(2004,2005)$.

\section{METODOLOGIA ${ }^{4}$}

Dos fatos estilizados e evidências em mercados agropecuários, depreende-se que os preços não são estacionários. E os retornos, os quais não podem ser previsíveis se os mercados forem eficientes, são ditos como uma sequência de diferença martingal. Justifica-se, portanto, o uso dos retornos sob a hipótese de diferença martingal para a eficiência do mercado. Pois, como os preços não são estacionários, é preferivel lidar com os retornos e, ao invés de testar se os preços seguem um processo martingal, testa-se se os retornos obedecem a uma sequência de diferenças martingal (Escanciano \& Lobato, 2009b).

Charles et al. (2011) sugerem o uso de duas classes de testes, de dependências lineares e não lineares, uma vez que possuem poder superior a suas respectivas dependências comparadas. Assim, adotam-se os testes de Escanciano \& Lobato (2009a) e Kim (2009), que mensuram a dependência linear, e os testes de Escanciano \& Velasco (2006) e Domínguez \& Lobato (2003) para dependência não linear, para as séries agropecuárias em análise. Note que em simulações de Monte Carlo, Charles et al. (2011) não encontraram evidências de distorção ao tamanho amostral para todos esses testes. Exceção, porém, ao teste proposto por Escanciano \& Lobato (2009a) que apresenta pouco sobredimensionamento, mas somente quando o tamanho da amostra é menor do que 100.

As inferências sobre eficiência relativa dos mercados são realizadas com adoção de janelamento móvel de subamostras a esses testes. Esse procedimento permite lidar com as mudanças contratuais ocorridas nos mercados agropecuários. Charles \& Darné (2009) sugerem o uso de janelas móveis nos testes para contornar os problemas advindos de mudanças estruturais devidas a eventos financeiros ou econômicos. Além disso, segundo Hsu \& Kuan (2005), ao validar os testes utilizando-se de subamostras de um grande conjunto de dados, permite-se lidar com os problemas advindos de data snooping. Para hierarquizar a eficiência dos mercados, utiliza-se o percentual dos testes estatisticamente significativos nas subamostras, que, segundo Lim \& Brooks (2011), permite uma indicação adequada na classificação quanto à eficiência dos mercados.

Para exemplificar a metodologia empregada neste estudo, denote $\left\{Y_{t}\right\}_{-\infty}^{\infty}$ como sendo uma série temporal estacionária. Segundo Charles et al. (2011), sob a hipótese de diferença martingal, $\mathbf{E}\left[Y_{t} \mid I_{t-1}\right]=\mu$; ou de forma equivalente $\mathbf{E}\left[\left(Y_{t}-\mu\right) \omega\left(I_{t-1}\right)\right]=0$, tal que $I_{t}=\left\{Y_{t}, Y_{t-1}, \ldots\right\}$ seja o conjunto de informações no tempo $t$ e $\omega(\cdot)$ uma função de ponderação $\omega\left(I_{t-1}\right)$ representa qualquer transformação linear ou não linear do passado.

\footnotetext{
${ }^{3} \mathrm{O}$ efeito data snooping ocorre quando uma base de dados é utilizada mais de uma vez, com o propósito de inferência ou seleção de um modelo. Assim, há possibilidade de que algum resultado satisfatório ocorra por acaso, ao invés do mérito inerente ao procedimento (White, 2000).

${ }^{4}$ Esta seção tem por fundamento as notações de Charles, Darné \& Kim (2011).
} 


\subsection{Testes com base em mensurações lineares à dependência}

Quando a função de ponderação assume a forma linear, $\omega\left(I_{t-1}\right)=Y_{t-1}$ para algum $i \geq 1$, a hipótese de diferença martingal implica que $\gamma_{i} \equiv \mathrm{E}\left[\left(Y_{t}-\mu\right)\left(Y_{t-i}-\mu\right)\right]=0$. Os testes portmanteau e de razão de variância dispostos a seguir têm $H_{0}: \rho(i) \equiv \gamma_{i} / \gamma_{0}=0$.

A estatística original do teste portmanteau pode ser escrita como

$$
Q_{p}=T \sum_{i=1}^{p} \hat{\rho}^{2}(i),
$$

tal que $\hat{\rho}(i)$ é a estimativa amostral de $\rho(i)$ e $T$ o tamanho amostral. Lobato, Nankervis \& Savin (2001) propõem sua versão robusta para o caso de $Y_{t}$ possuir heterocedasticidade condicional, que pode ser escrita como

$$
Q_{p}^{*}=T \sum_{i=1}^{p} \tilde{\rho}^{2}(i),
$$

tal que $\tilde{\rho}(i)=\hat{\gamma}^{2}(i) / \hat{\tau}(i) ; \hat{\gamma}(i)$ é a autocovariância amostral de $Y_{t}$; e $\hat{\tau}(i)$ a autocovariância amostral de $Y_{t}^{2}$.

Para evitar uma seleção ad hoc de $p$ em (2), utiliza-se o procedimento de Escanciano \& Lobato (2009a). Esses autores propõem um teste automático em que o valor ótimo de $p$ é determinado por um procedimento totalmente dependente dos dados. A estatística do teste, que segue uma distribuição assintótica $\chi_{1}^{2}$, pode ser escrita como

$$
A Q=Q_{\tilde{p}}^{*}
$$

tal que $\tilde{p}=\min \left\{p: 1 \leq p \leq d ; L_{p} \geq L_{h}, h=1,2, \ldots, d\right\}, d$ um limite superior fixo, enquanto $L_{p}=Q_{p}^{*}-$ $\pi(p, T)$, onde o termo de penalidade $\pi(p, T, q)=p \log (T)$ se $\max _{1 \leq i \leq d} \sqrt{T}|\tilde{\rho}(i)| \leq \sqrt{2.4 \log (T)}$ e caso contrário $\pi(p, T, q)=2 p$.

A estatística de razão de variância pode ser escrita como

$$
\widehat{V R}(k)=1+2 \sum_{i=1}^{k-1}\left(1-\frac{i}{k}\right) \hat{\rho}(i),
$$

tal que $k$ denota o holding period. Choi (1999) propõe um teste automático de razão de variância em que $k$ é escolhido de forma ótima, utilizando o método totalmente dependente dos dados com base em Andrews (1991). Kim (2009) mostra que as propriedades em pequenas amostras do teste de Choi (1999) podem ser melhoradas ao se aplicar o wild bootstrap. ${ }^{5}$ Seja $A V R$ a estatística do teste com a escolha ótima de $k$ denotado por $A V R\left(k^{*}\right)$. O teste automático com wild bootstrap de Kim (2009) segue três estágios:

(i) formar uma amostra de bootstrap de $T$ observações $Y_{t}^{*}=\eta_{t} Y_{t}(t=1, \ldots, T)$, tal que $\eta_{t}$ é uma variável aleatória com média zero e variância unitária;

(ii) calcular $A V R^{*}\left(k^{*}\right)$, a estatística $A V R\left(k^{*}\right)$ é calculada de $\left\{Y_{t}\right\}_{t=1}^{T}$;

(iii) repetir o primeiro e segundo procedimento $B$ vezes para formar uma distribuição bootstrap

$$
\left\{A V R^{*}\left(k^{*} ; j\right)\right\}_{j=1}^{B}
$$

para a estatística do teste.

Para testar $H_{0}$, o valor- $p$ é calculado como uma proporção dos valores absolutos de $\left\{A V R^{*}\left(k^{*} ; j\right)\right\}_{j=1}^{B}$ maiores que o valor absoluto observado da estatística $A V R\left(k^{*}\right)$.

\footnotetext{
${ }^{5}$ Note que esse procedimento é computacionalmente intensivo e, sob janelamento móvel de subamostras, requer dias para sua conclusão.
} 


\subsection{Testes com base em mensurações não lineares à dependência}

Para o caso de funções de ponderação não lineares, procede-se aos testes de Escanciano \& Velasco (2006) e Domínguez \& Lobato (2003), com funções exponencial e indicadora, respectivamente. O primeiro para detectar dependência média condicional não linear geral, e o segundo para testar predicabilidade não direcional.

Escanciano \& Velasco (2006) expressam a hipótese nula de diferença martingal em forma de uma função de regressão par-a-par. Isto é, $H_{0}: m_{j}(y)=0$, em que

$$
m_{j}(y)=\mathrm{E}\left[Y_{t}-\mu \mid Y_{t-j}=y\right]
$$

contra $H_{1}: \mathrm{P}\left(m_{j}(y) \neq 0\right)>0$ para algum $j$. A hipótese nula é consistente com a função exponencial de ponderação

$$
\gamma_{j}(x) \equiv \mathbf{E}\left[\left(Y_{t}-\mu\right) e^{i x Y_{t-j}}\right]=0
$$

tal que $\gamma_{j}(x)$ representa uma mensuração da autocovariância sob abordagem não linear, com $x$ sendo qualquer valor real. Escanciano \& Velasco (2006) propõem o uso de uma função de distribuição espectral generalizada, na qual a estimativa amostral pode ser escrita como

$$
\hat{H}(\lambda, x)=\hat{\gamma}_{0}(x) \lambda+2 \sum_{j=1}^{T-1}\left(1-\frac{j}{T}\right)^{0,5} \hat{\gamma}_{j}(x) \frac{\operatorname{sen}(j \pi \lambda)}{j \pi},
$$

onde

$$
\hat{\gamma}_{j}(x)=\frac{1}{T-j} \sum_{t=1+j}^{T}\left(Y_{t}-\bar{Y}_{T-j}\right) e^{i x Y_{t-j}} \quad \text { e } \quad \bar{Y}_{T-j}=\frac{1}{T-j} \sum_{t=1+j}^{T} Y_{t} .
$$

A estatística do teste para $H_{0}$ é

$$
S_{T}(\lambda, x)=\left(\frac{T}{2}\right)^{0,5}\left\{\hat{H}(\lambda, x)-\hat{H}_{0}(\lambda, x)\right\}=\sum_{j=1}^{T-1}(T-j)^{0,5} \hat{\gamma}_{j}(x) \frac{\sqrt{2} \operatorname{sen}(j \pi x)}{j \pi},
$$

pois a hipótese nula é equivalente a $H(\lambda, x)=\gamma_{0}(x) \lambda$. Então o teste é realizado com base na discrepância entre $\hat{H}(\lambda, x)$ e $\hat{H}_{0}(\lambda, x):=\hat{\gamma}_{0}(x) \lambda$.

Para avaliar o valor de $S_{T}$ entre todos os possíveis valores de $\lambda$ e $x$, Escanciano \& Velasco (2006) utilizam a norma de Cramer-von Mises para obter a estatística

$$
D_{T}^{2}=\sum_{j=1}^{T-1} \frac{T-j}{(j \pi)^{2}} \sum_{t=j+1}^{T} \sum_{s=j+1}^{T}\left(Y_{t}-\bar{Y}_{T-j}\right)\left(Y_{s}-\bar{Y}_{T-j}\right) \exp \left(-0,5\left(Y_{t-j}-Y_{s-j}\right)^{2}\right) .
$$

Domínguez \& Lobato (2003) consideram o caso da função indicadora e propõem o teste $D L$ com base nas estatísticas Cramer-von Mises $(C v M)$ e Kolgomorov-Smirnov $(K S)$, que podem ser escritas como

$$
\begin{gathered}
C v M_{T, p}=\frac{1}{\hat{\sigma}^{2} T^{2}} \sum_{j=1}^{T}\left[\sum_{t=1}^{T}\left(Y_{t}-\bar{Y}\right) I\left(\tilde{Y}_{t, p} \leq \tilde{Y}_{j, p}\right)\right]^{2}, \\
K S_{T, p}=\max _{1 \leq i \leq T}\left|\frac{1}{\hat{\sigma} \sqrt{T}} \sum_{t=1}^{T}\left(Y_{t}-\bar{Y}\right) I\left(\tilde{Y}_{t, p} \leq \tilde{Y}_{j, p}\right)\right|,
\end{gathered}
$$

em que $\tilde{Y}_{t, p}=\left(Y_{t-1}, \ldots, Y_{t-p}\right)$ são os valores das $p$-defasagens.

As estatísticas dos testes $G S$ e $D L$ não possuem distribuições assintóticas-padrão. Para implementálas em amostras finitas, os autores recomendam o uso do wild bootstrap. O valor- $p$ do teste é obtido por distribuições bootstrap, de forma similar aos três estágios descritos no teste $A V R$. 


\section{A HIPÓTESE ADAPTATIVA DOS MERCADOS AGROPECUÁRIOS BRASILEIROS}

A eficiência de um mercado é altamente dependente do contexto e das dinâmicas dos mercados. Apesar de a hipótese adaptativa de eficiência estar em desenvolvimento, e certamente necessitar de mais pesquisas, suas implicações podem ser derivadas com base na análise empírica das forças evolutivas nos mercados (Lo, 2004, 2005). Nesse sentido, utiliza-se para a análise da eficiência dos mercados agropecuários brasileiros a evolução dos números de contratos negociados e dos tipos de participantes nesses mercados, os quais se referem aos contratos futuros agropecuários lançados pela Bolsa entre 2000 e 2013 e atualmente vigentes. A formação da base de dados foi realizada por meio do sistema de recuperação de dados da BM\&FBOVESPA, a qual permite avaliar a dinâmica dos lançamentos contratuais efetuados pela Bolsa.

Essa constatação pode ser visualizada na Figura 1. Ela apresenta o número total de contratos negociados em todos os vencimentos, desde 2000 até 2013, para todos os ativos agropecuários negociados no período. Nota-se a predominância das negociações do café (ICF) até o período 2006. Após esse período, o café passou a ser menos representativo no total de negócios, tornando-se o segundo ativo com maior número de negócios. Após 2006, o contrato de boi gordo (BGI), lançado em 2000, passou a ser o mais negociado. Nota-se também a mudança do contrato anterior de boi gordo (ILC), para o vigente. Enquanto aquele estava na segunda posição em contratos negociados, este passa a ser o contrato com maior representatividade em 2007. Comparando os contratos de café e de boi gordo com os outros ativos, pode-se considerá-los como os contratos de maior sucesso em relação à quantidade numérica de contratos negociados, bem como em sua representatividade no mercado futuro agropecuário brasileiro, no período em análise.

Em relação aos demais contratos dispostos na Figura 1, percebem-se as tentativas da Bolsa em consolidar outros ativos agropecuários, com os lançamentos e mudanças nos contratos de etanol, soja e milho. Este último passou a ter participação preponderante nos negócios totais, atingindo a primeira posição no final do período. Enquanto os contratos de café perderam participação relativa, outros ativos como os de açúcar, algodão e bezerro tiveram seus contratos descontinuados. Ressalta-se que esses contratos descontinuados, durante seus períodos de vigência na amostra, assim como os contratos de soja e etanol, relacionam-se com ínfimas quantidades de contratos negociados, o que pode dificultar o funcionamento informacional adequado contido nos preços desses ativos.

Diante dessa "dinâmica", pode-se inferir que os mercados agropecuários brasileiros possuem características da adaptabilidade dos agentes às mudanças no ambiente dos mercados, assim como da Bolsa, que se adapta às preferências de negociação dos agentes, ao alterar, lançar, ou, até mesmo, descontinuar os contratos, o que sugere uma perspectiva adaptativa à eficiência dos mercados agropecuários brasileiros. Conforme ressalta Lo $(2004,2005)$, a existência de um mercado ativo e líquido implica que as oportunidades de lucro devem estar presentes. À medida que são exploradas, essas oportunidades desaparecem. Mas novas oportunidades são também criadas continuamente conforme ocorram mudanças nas instituições, nas condições dos mercados e nas mudanças dos agentes.

As mudanças dos agentes nos mercados agropecuários brasileiros podem ser visualizadas na Figura 2, que dispõe os tipos de participantes dos contratos em aberto para todos os vencimentos. A BM\&FBOVESPA disponibiliza a divisão dos tipos de participantes em: Pessoas Jurídicas Financeiras, Investidores Institucionais, Investidores Não Residentes, Pessoas Jurídicas Não Financeiras e Pessoas Físicas. Dessa subdivisão, pode-se supor que as Pessoas Jurídicas Não Financeiras e parte das Pessoas Físicas são consideradas como hedgers, enquanto que os demais supõe-se serem especuladores.

Nota-se que os tipos de participantes e suas respectivas representações nos totais de contratos em aberto, de forma geral, não são estáveis e se alteram ao longo do tempo, conforme prediz a hipótese adaptativa dos mercados de Lo $(2004,2005)$. Segundo esses estudos, as estratégias de investimentos passam por ciclos de ganhos e perdas em resposta às mudanças dos competidores (agentes) saindo e entrando nos mercados, bem como das magnitudes e dos tipos de oportunidades de ganhos financeiros. Assim, como as oportunidades são variáveis, o mesmo ocorre com os agentes afetados. 
Figura 1. Número de contratos agropecuários negociados de todos os vencimentos.
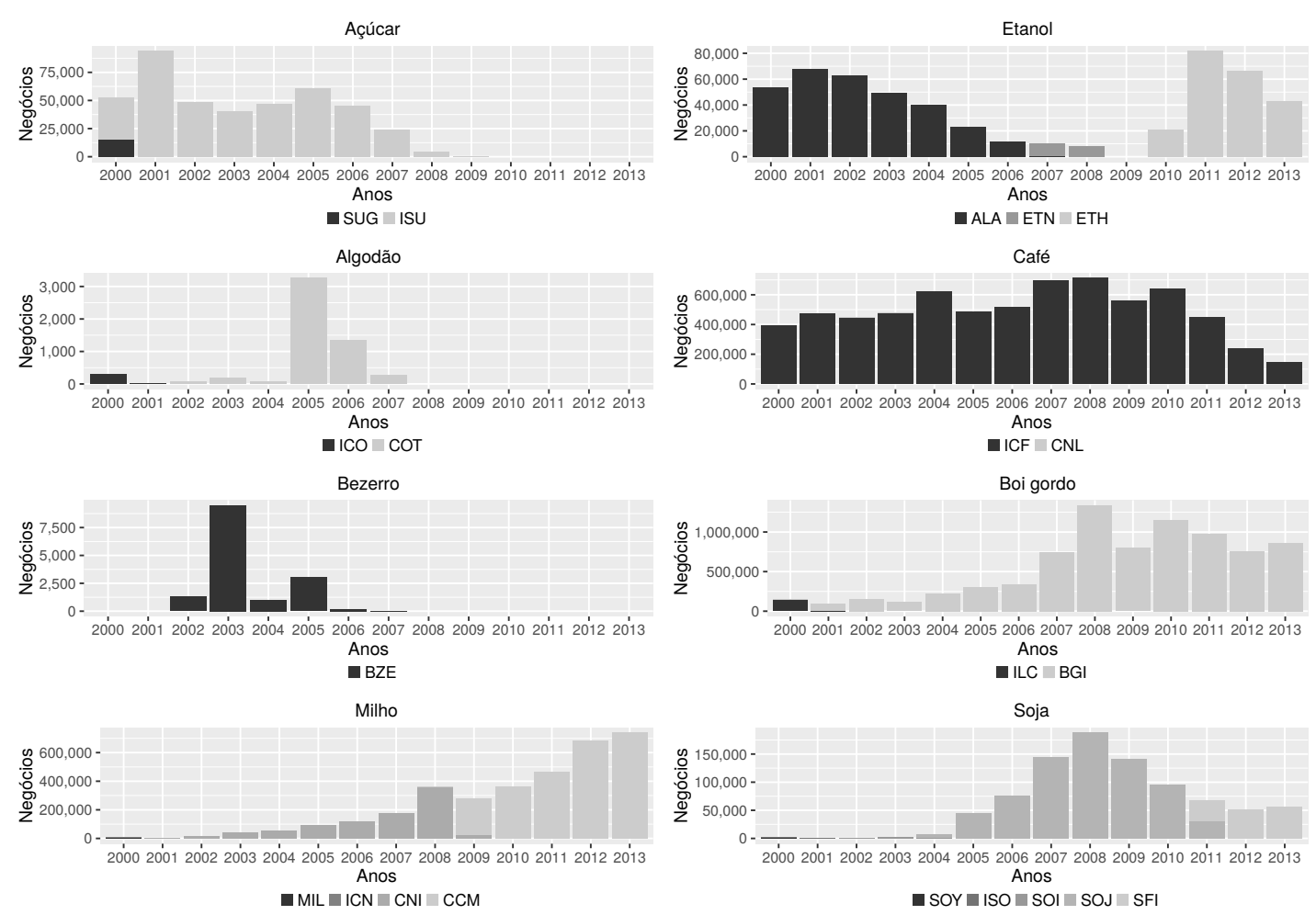

Nota: Os ativos são representados pelas tonalidades de cinza: açúcar (SUG e ISU), algodão (ICO e COT), etanol (ALA, ETN e ETH), café (ICF e CNL), boi gordo (ILC e BGI), bezerro (BZE), milho (MIL, ICN, CNI e CCM) e soja (ISO, SOI, SOJ e SFI).

Fonte: Dados da Pesquisa.

Espera-se, de um contrato bem-sucedido e informacionalmente eficiente, a atração heterogênea de participantes, com propósitos diferentes, seja para hedging ou especulação, assim como a não concentração dos contratos negociados em diferentes tipos de agentes. Percebe-se visualmente na Figura 2 que isso ocorre de forma mais frequente nos contratos de café, boi gordo e recentemente no contrato de milho.

Nota-se que até a metade do período amostral do café houve um quadro evolutivo de diversificação do tipo de participantes, com destaque aos investidores não residentes. No entanto, nos anos mais recentes ocorreu uma concentração dos contratos em aberto por parte das pessoas jurídicas não financeiras, conforme havia no início amostral. Essa concentração pode sugerir menor eficiência informacional contida nos preços, uma vez que ocorreu menor diversificação de agentes com finalidades distintas. Segundo Lo (2005), os preços refletem o máximo de informações sujeitas às combinações informacionais contidas no ambiente e no número de agentes do mercado. Caso inúmeros agentes concorram na obtenção dos recursos (lucros) nesse mercado, o mercado deverá ser altamente eficiente. Por outro lado, em situações de pequenas quantidades de agentes competindo na obtenção de recursos, o mercado deverá ser considerado menos eficiente.

Por exemplo, no mercado de boi gordo, o maior número de participantes no início amostral foi de pessoas fisicas. Ao longo do tempo, houve maior diversificação nos tipos de agentes operando nesse mercado. Destacam-se nesta representatividade os investidores institucionais e pessoas jurídicas financeiras, os quais podem ser classificados como especuladores. 
Figura 2. Tipos de participantes dos contratos em aberto para todos os vencimentos.

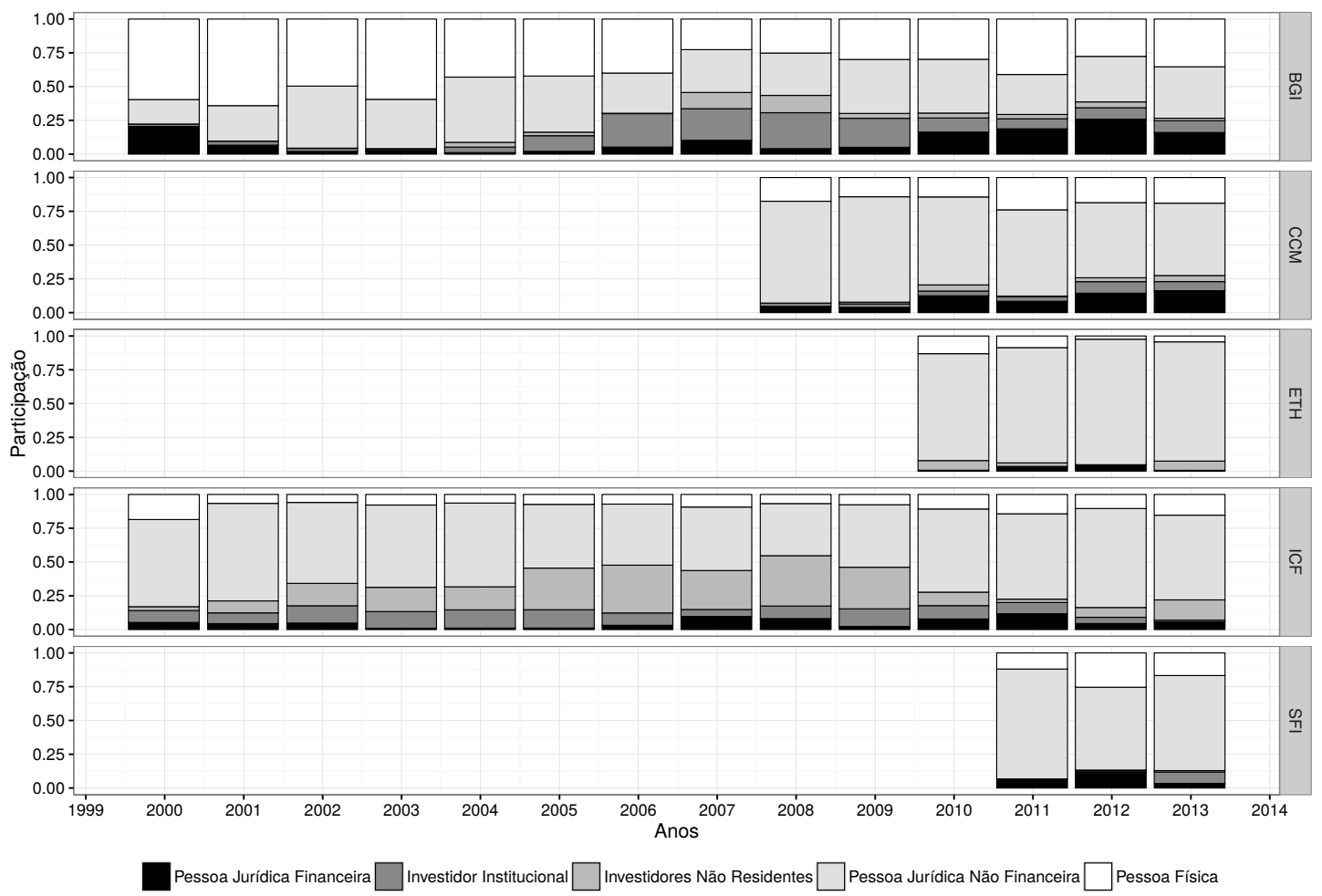

Fonte: Dados da Pesquisa.

Participação crescente dos investidores institucionais e a de pessoas jurídicas não financeiras também ocorreram no mercado de milho. Enquanto que, nos contratos de soja e, em particular, no mercado de etanol, tais contratos não podem ser caracterizados com dispersões entre os tipos de participantes. Assim, espera-se que com pouca diversificação de agentes, esses últimos contratos sejam informacionalmente menos eficientes ao compará-los com contratos de maior diversificação dos tipos de agentes.

Para demonstrar a diversificação negocial por participantes, computa-se o coeficiente de Gini supondo a existência agregada de apenas esses cinco agentes, com respeito à quantidade de contratos em aberto por esses agentes agregados. Observa-se que, nos períodos expostos, os mercados menos desiguais foram: boi gordo $(0,32)$, café $(0,44)$, milho $(0,56)$, soja $(0,61)$ e etanol $(0,71)$. Disso, pode-se inferir que há maior competição no mercado de boi gordo e menor competição no mercado de etanol.

\subsection{A hipótese adaptativa dos mercados sob dependências lineares e não lineares}

Os contratos futuros de boi gordo (BGI) e café (ICF), atualmente negociados na BM\&FBOVESPA, começaram a ser negociados no dia 25 de setembro de 2000 e 8 de dezembro de 1999, respectivamente. Para comparações diante dessa diferença de datas iniciais de negociação, escolheu-se como início às séries o primeiro dia de negociação do contrato BGI. Justifica-se a escolha desses dois ativos agropecuários pois foram historicamente os mais negociados na Bolsa de futuros brasileira (Figura 1). Além disso, esses ativos possuem séries mais longas, sem mudança na nomenclatura de negociação, boi gordo (BGI) e café (ICF), o que permite analisar a eficiência do mercado futuro agropecuário brasileiro com periodicidade equivalente. 
Optou-se por não considerar os ativos com contratos descontinuados pela Bolsa nesse período, conforme disposto na Figura 1, tais como: açúcar, algodão e bezerro. Outros ativos como soja, milho e etanol, atualmente transacionados na Bolsa, não possuem séries tão longas e contínuas como as do boi gordo e do café. Por esse motivo, a análise divide-se em duas subamostras, conforme mostra a Tabela 2. A primeira amostra compreende os retornos no período de 26 de setembro de 2000 a 30 de dezembro de 2013 , com os ativos boi gordo e café, os quais possuem séries mais longas e contínuas. A segunda compreende os retornos no período de 28 de janeiro de 2011 a 30 de dezembro de 2013, à qual se adicionam os ativos etanol, milho e soja. Para serem comparáveis, escolheu-se como início dessa amostra o primeiro dia de negociação do atual contrato de soja (SFI). Ademais, essas séries são mais curtas devido à mudança em suas nomenclaturas contratuais, caracterizando contratos como mais recentes do que os de boi gordo e café.

Utilizando o percentual de dias com retornos iguais a zero, medida proposta por Lesmond, Ogden \& Trzcinka (1999), como proxy para a liquidez dos contratos, houve uma redução na liquidez dos contratos de café entre as duas subamostras e um ganho na liquidez no contrato de boi gordo. Ademais, o percentual de dias com retornos iguais a zero para o contrato de milho assemelha-se aos contratos de boi gordo e de café. Discrepância pode ser observada no contrato de soja, e, em particular, no de etanol, cujo contrato teve aproximadamente $14 \%$ dos dias de negociação com retornos iguais a zero. Pode-se inferir, a partir desses valores, que os contratos de soja e etanol podem ser considerados como menos líquidos e, portanto, influenciando de forma negativa a eficiência informacional de seus mercados.

A BM\&FBOVESPA atribui limites de oscilações diárias nos cinco contratos futuros agropecuários: café (9\%), boi gordo (3,5\%), milho (5\%), etanol $(6,5 \%)$ e soja (5\%). Lim \& Brooks (2011) ressaltam que a literatura acadêmica evidencia que os limites de oscilação atribuídos pelas Bolsas influenciam a eficiência dos mercados. Essa literatura revista pelos autores aponta que os limites impostos pelas Bolsas previnem que os preços atinjam seu nível de equilíbrio e que o relaxamento dos limites tende a diminuir sua influência na eficiência dos mercados. Apesar de existirem esses limites atribuídos pela BM\&FBOVESPA, as especificações dos contratos permitem que nos últimos três dias não haja limite de oscilação nos ajustes diários. De acordo com os mínimos e máximos dispostos na Tabela 2, houve retornos fora desses limites, em particular, coincidentes com os últimos dias de negociação. Essa característica pode ser atribuída ao efeito expiração dos contratos futuros, no qual ocorrem maiores variações abruptas.

Tabela 2. Análise preliminar das séries de retornos.

\begin{tabular}{lccccccc}
\hline & ICF.1 & BGI.1 & ICF.2 & BGI.2 & CCM.2 & ETH.2 & SFI.2 \\
\hline Início amostral & $2000-09-26$ & $2000-09-26$ & $2011-01-28$ & $2011-01-28$ & $2011-01-28$ & $2011-01-28$ & $2011-01-28$ \\
Final amostral & $2013-12-30$ & $2013-12-30$ & $2013-12-30$ & $2013-12-30$ & $2013-12-30$ & $2013-12-30$ & $2013-12-30$ \\
Observações & 3.283 & 3.283 & 725 & 725 & 725 & 725 & 725 \\
Retornos =0 (\%) & 1,7661 & 3,0450 & 2,2038 & 1,5151 & 2,2038 & 14,8760 & 6,8870 \\
Mínimo & $-0,0868$ & $-0,1049$ & $-0,0588$ & $-0,0466$ & $-0,1248$ & $-0,3352$ & $-0,1555$ \\
Máximo & 0,1224 & 0,0862 & 0,0644 & 0,0616 & 0,1264 & 0,0629 & 0,0401 \\
Média & $1 e-4$ & $3 e-4$ & $-0,0011$ & $2 e-4$ & $-1 e-4$ & $1 e-4$ & $-1 e-4$ \\
Variância & $4 e-4$ & $1 e-4$ & $3 e-4$ & $1 e-4$ & $2 e-4$ & $4 e-4$ & $2 e-4$ \\
Assimetria & 0,4285 & 0,1801 & 0,19 & 1,0327 & $-1,0132$ & $-11,2105$ & $-3,609$ \\
Curtose & 5,8593 & 17,5688 & 4,011 & 18,2519 & 22,6301 & 187,9388 & 39,6491 \\
Jarque-Bera & $1.218,8013$ & $29.051,8077$ & 35,2402 & $7.155,9873$ & $11.764,5542$ & $1.048 .382,2273$ & $42.148,3134$ \\
Valor- $p$ & 0 & 0 & 0 & 0 & 0 & 0 & 0 \\
Doornik-Hansen & 479,9946 & $5.173,4923$ & 25,7347 & 900,6504 & $1.314,4474$ & $19.147,4891$ & 403,8372 \\
Valor- $p$ & 0 & 0 & 0 & 0 & 0 & 0 & 0 \\
\hline
\end{tabular}

Notas: ICF, BGI, CCM, ETH e SFI denotam os contratos de café, boi gordo, milho, etanol e soja, respectivamente. 0 números 1 e 2 após os códigos dos contratos representam, respectivamente, os períodos amostrais ( 26 de setembro de 2000 a 30 de dezembro de 2013 ) e (28 de janeiro de 2011 a 30 de dezembro de 2013). 
Como esperado, a média dos retornos para todas as séries é próxima de zero. Adicionalmente, assim como Choi (1999), testou-se a hipótese nula de média zero para os retornos com o uso do teste- $t$, uma vez que os testes à hipótese martingal pressupõem média zero. Os resultados dão suporte a essa suposição com $1 \%$ de significância estatística. Em relação à variância, nota-se que as séries do café e do etanol apresentam maiores flutuações, enquanto a série do boi gordo apresenta comportamento mais estável.

Nota-se que as características das séries, reportadas nos terceiros e quarto momentos, indicam que os fenômenos extremos ocorrem com maior frequência do que predito por uma distribuição normal, uma vez que as séries apresentaram excesso de curtose. Além disso, os aumentos abruptos nos preços dos contratos de café e boi gordo ocorrem com maior frequência do que as quedas abruptas, indicadas pela associação de assimetria positiva. O inverso ocorre nos contratos de milho, etanol e soja, com assimetria negativa. Segundo Cont (2001), essas características podem ser consideradas como das mais importantes em séries temporais financeiras, devido à elevada variabilidade, relevada por caudas pesadas nas distribuições e a probabilidade de ocorrência de movimentos abruptos nos mercados.

Como indicado pelas medidas de assimetria e curtose, as estatísticas dos testes Jarque-Bera e de Doornik \& Hansen (2008) rejeitam a hipótese nula de normalidade para todas as séries de retorno, a 1\% de significância estatística, indicando que os retornos dos contratos futuros agropecuários de café, boi gordo, milho, etanol e soja não são normais. Portanto, as estatísticas sugerem que a suposição de normalidade dessas séries de tempo é restritiva, o que foi ressaltado nos surveys de Cont (2001) e de Lim \& Brooks (2011). Segundo Escanciano \& Lobato (2009b), os testes iniciais para verificar as dependências lineares das séries foram motivados por observações empíricas em que as séries de tempo seguem distribuições normais. No entanto, as evidências de não normalidade das séries reportadas na Tabela 2 roboram o uso dos testes lineares robustos à presença de dependências não lineares, bem como dos testes que consideram essas dependências não lineares, conforme sugerido por Escanciano \& Lobato (2009b) e discutidos nas seções 3.1 e 3.2, respectivamente.

Os argumentos de Escanciano \& Lobato (2009b) sugerem uma condição necessária (mas não suficiente, em geral) para que a hipótese de diferença martingal seja verdadeira: as séries de tempo sejam não correlacionadas. Comparando as estatísticas propostas por Fisher \& Gallagher (2012) e dispostas na Tabela 3, entre os dois períodos do boi gordo, verifica-se a presença de autocorrelação linear estatisticamente significativa a $1 \%$ no primeiro período (mais longo) mas não no segundo período (mais curto). Para as séries de milho e etanol, também se verifica a presença de autocorrelação estatisticamente significativa ao mesmo nível de significância. Para as demais séries, café e soja, não há presença dessa dependência linear significativa. Tais evidências contrastam com um dos fatos estilizados normalmente presentes nas séries de retornos e indicado por Cont (2001): a insignificância estatística das autocorrelações lineares.

A falta de autocorrelações significativas dos retornos proporciona uma evidência empírica para a eficiência desses mercados. Entretanto, conforme ressalta Cont (2001), isso não implica independência dos incrementos: independência implica que quaisquer funções não lineares dos retornos também não devem possuir autocorrelações. Conforme as estatísticas de Fisher \& Gallagher (2012), verifica-se presença de heterocedasticidade estatisticamente significativa a $1 \%$ apenas para a amostra mais longa de dados. Assim, evidencia-se comportamento não linear para as séries longas do café e do boi gordo. Essa característica, conhecida como cluster de volatilidade, significa que grandes variações dos preços possuem maior probabilidade de serem seguidas por outras grandes variações. Segundo Lobato et al. (2001), essa é uma característica bem conhecida de retornos financeiros: substancial autocorrelação dos retornos ao quadrado. Segundo os autores, isso implica que, mesmo que os retornos do café sejam não correlacionados, há dependência estatística. Portanto, a não evidência de autocorrelação dos retornos ao quadrado para a amostra mais curta se contrapõe a um dos fatos estilizados dos retornos: cluster de volatilidade.

Garcia et al. (1988) sugerem que a não aleatoriedade dos mercados se faz mais presente do que tradicionalmente se mensura e que essas dependências podem ter naturezas não lineares. Além das evidências reportadas para essas dependências, por meio dos testes sob os retornos ao quadrado, adotase, assim como Lim et al. (2013), o teste BDS proposto por Broock et al. (1996). Segundo Broock et al. 
Tabela 3. Estatísticas de autocorrelação, heterocedasticidade e não lineariedade.

\begin{tabular}{lccccccc}
\hline & ICF.1 & BGI.1 & ICF.2 & BGI.2 & CCM.2 & ETH.2 & SFI.2 \\
\hline Ljung-Box ponderado $\left(\tilde{Q}_{W}\right)$ & 4,6932 & 42,9813 & 3,9345 & 3,3269 & 22,5299 & 15,9577 & 5,6682 \\
Valor- $p$ & 0,4758 & 0 & 0,4312 & 0,5381 & 0 & $8 e-4$ & 0,2079 \\
Monti ponderado $\left(\tilde{M}_{W}\right)$ & 4,7345 & 39,3428 & 3,9367 & 3,2789 & 19,232 & 15,349 & 5,5017 \\
Valor- $p$ & 0,4694 & 0 & 0,4308 & 0,5471 & $1 e-4$ & 0,0011 & 0,2241 \\
Ljung-Box ponderado ${ }^{*}\left(\tilde{Q}_{W}^{*}\right)$ & 85,7518 & 24,4218 & 4,5296 & 0,3213 & 1,6843 & 0,2075 & 0,1184 \\
Valor- $p$ & 0 & 0 & 0,3405 & 0,9972 & 0,854 & 0,9991 & 0,9998 \\
Monti ponderado ${ }^{*}\left(\tilde{M}_{W}^{*}\right)$ & 70,6429 & 20,9285 & 4,6714 & 0,3213 & 1,6126 & 0,2088 & 0,1186 \\
Valor- $p$ & 0 & $1 e-4$ & 0,3211 & 0,9972 & 0,8662 & 0,9991 & 0,9998 \\
BDS $\epsilon=1, m=2$ & 3 & 10 & 2 & 3 & 6 & 5 & 4 \\
Valor- $p$ & 0 & 0 & 0 & 0 & 0 & 0 & 0 \\
BDS $\epsilon=1, m=3$ & 3 & 15 & 1 & 3 & 8 & 5 & 4 \\
Valor- $p$ & 0 & 0 & 0 & 0 & 0 & 0 & 0 \\
BDS $\epsilon=2, m=2$ & 3 & 8 & 2 & 2 & 6 & 5 & 4 \\
Valor- $p$ & 0 & 0 & 0 & 0 & 0 & 0 & 0 \\
BDS $\epsilon=2, m=3$ & 3 & 11 & 1 & 2 & 8 & 5 & 4 \\
Valor- $p$ & 0 & 0 & 0 & 0 & 0 & 0 & 0 \\
\hline
\end{tabular}

Notas: ICF, BGI, CCM, ETH e SFI denotam os contratos de café, boi gordo, milho, etanol e soja, respectivamente. Os números 1 e 2 após os códigos dos contratos representam, respectivamente, os períodos amostrais (26 de setembro de 2000 a 30 de dezembro de 2013) e (28 de janeiro de 2011 a 30 de dezembro de 2013). Ljung-Box ponderado $\left(\tilde{Q}_{W}\right)$ e Monti ponderado $\left(\tilde{M}_{W}\right)$ denotam as estatísticas propostas por Fisher \& Gallagher (2012). Os sobrescritos * denotam essas estatísticas com base nos resíduos ao quadrado. A estatística de Broock, Scheinkman, Dechert \& LeBaron (1996) é representada por BDS.

(1996), o teste BDS pode ser utilizado para verificar a não linearidade e pode ser considerado como uma estatística não linear análoga à estatística $Q$ da família Box-Pierce. Os resultados das estatísticas BDS para $\epsilon=\left\{\frac{1}{2} \sigma, 1 \sigma\right\}$ com $m=\{2,3\}$ indicam natureza não linear dos retornos a $1 \%$ de significância estatística.

Os testes apresentados para autocorrelação, heteroscedastícia e não linearidade auxiliam na identificação de dependências lineares e não lineares para a análise subsequente da hipótese adaptativa dos mercados. Mas possuem algumas deficiências tais como: pontos de corte e número de lags arbitrários, conforme ressalta Choi (1999). Uma vez identificadas essas dependências, lineares e não lineares, devem-se, portanto, considerar os testes para a hipótese de diferença martingal que sejam robustos a essas características. Dessa forma, procede-se, conforme exposto na seção 3 e segundo Charles et al. (2012), com os testes para a hipótese de diferença martingal robustos a essas características das séries.

\subsubsection{Janelamento móvel de subamostras}

Os testes de dependências lineares, propostos por Escanciano \& Lobato (2009a) e Kim (2009), assim como os testes de dependências não lineares, propostos por Escanciano \& Velasco (2006) e Domínguez \& Lobato (2003), foram realizados em janelamentos de 100 subamostras com 10.000 replicações de bootstrap. A escolha do janelamento deu-se com base nas simulações de Monte Carlo de Charles et al. (2011), as quais não encontraram distorções amostrais para os testes acima de 100 observações. Ao serem implementadas as rolagens em subamostras, essa abordagem permite inferências robustas contra possíveis mudanças estruturais, além de viabilizarem a comparação sobre a eficiência relativa dos mercados.

Uma vez que seria inviável reportar todos os resultados dos testes para cada janelamento de subamostras, os valores- $p$ desses são reportados em forma gráfica, conforme disposto nas Figuras 3 e 4 . O eixo vertical mostra os valores- $p$, o eixo horizontal refere-se à última observação do período de janelamento 
Figura 3. Valores-p das estatísticas Escanciano \& Lobato (2009a), Kim (2009), Escanciano \& Velasco (2006) e Domínguez \& Lobato (2003) em janelas móveis de subamostras para os contratos de café (ICF.1) e boi gordo (BGI.1) entre 21 de junho de 2001 e 30 de dezembro de 2013.

(a) ICF.1

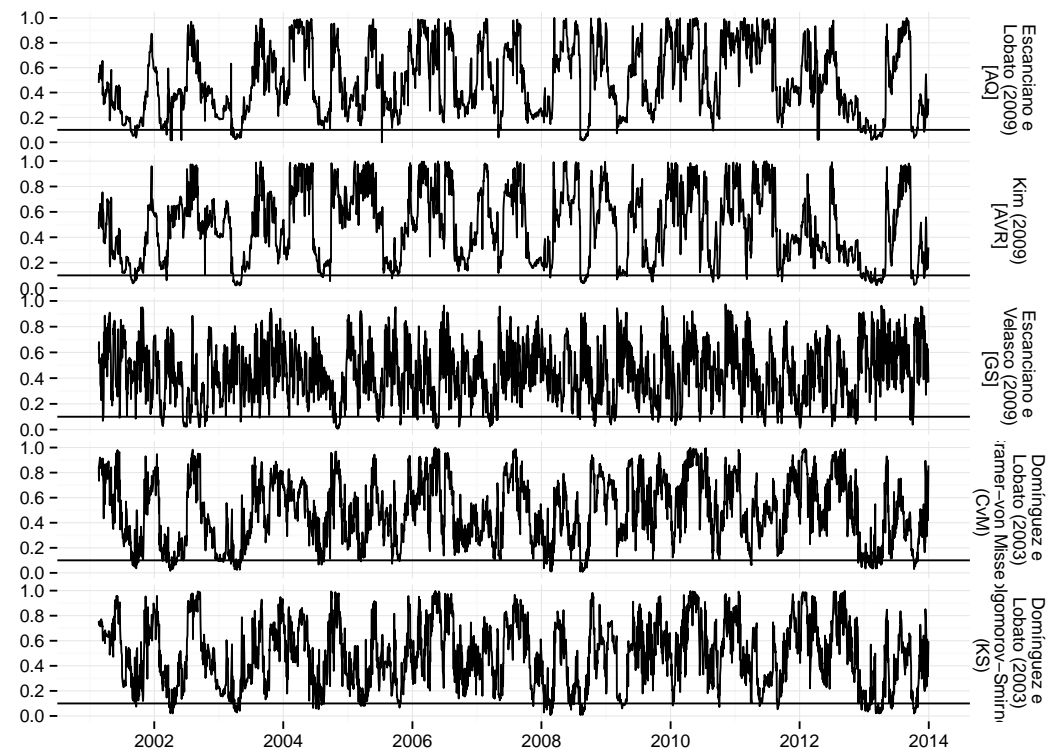

(b) BGI.1

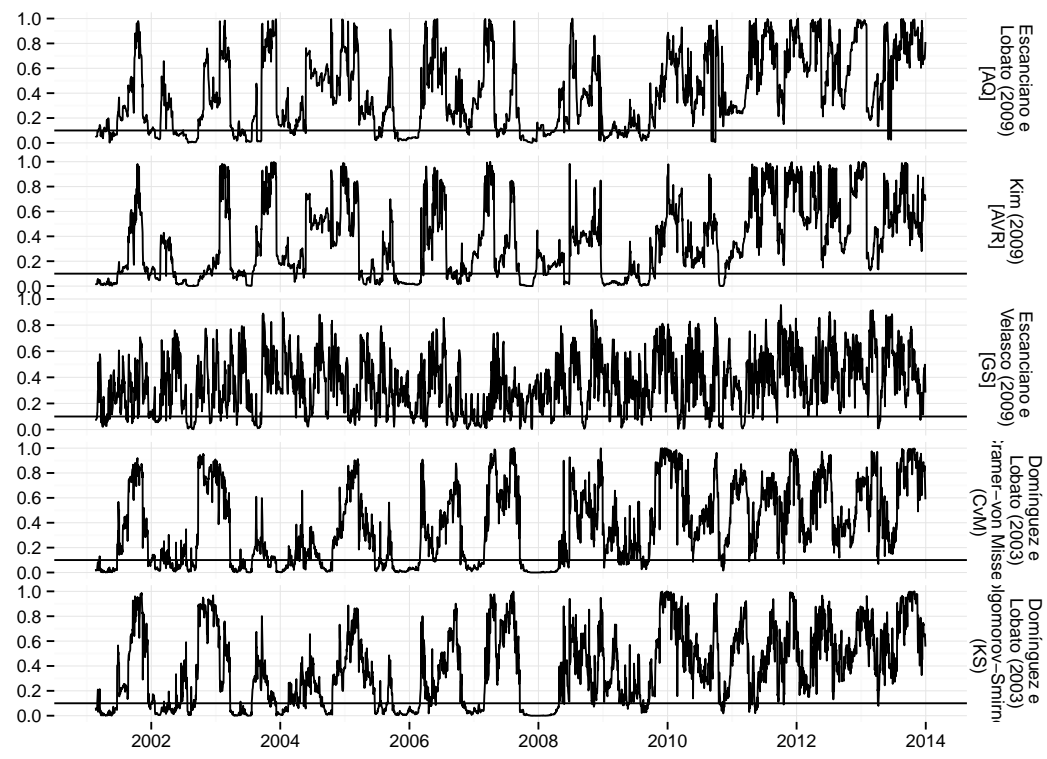

Nota: Os valores- $p$ dispostos correspondem à data final de cada janelamento móvel de 100 subamostras, referentes ao intervalo entre 21 de junho de 2001 a 30 de dezembro de 2013. Os testes sob dependências lineares referem-se a $Q_{\tilde{p}}^{*}$ e $A V R^{*}$. $Q_{\tilde{p}}^{*}$ denota o teste de Escanciano \& Lobato (2009a). $A V R^{*}$ denota o teste de Kim (2009). Os testes de dependências não lineares referem-se a $D_{T}^{2}$, $C v M$ e $K S . D_{T}^{2}$ denota o teste de Escanciano \& Velasco (2006), $C v M$ e $K S$ denotam os testes de Domínguez \& Lobato (2003), com base nas estatísticas Cramer-von Mises e Kolgomorov-Smirnov, respectivamente. 
Figura 4. Valores-p das estatísticas Escanciano \& Lobato (2009a), Kim (2009), Escanciano \& Velasco (2006) e Domínguez \& Lobato (2003) em janelas móveis de subamostras para os contratos de café (ICF.2), boi gordo (BGI.2), milho (CCM.2), etanol (ETH.2) e soja (SFI.2) entre 22 de junho de 2011 e 30 de dezembro de 2013.

(a) ICF.2

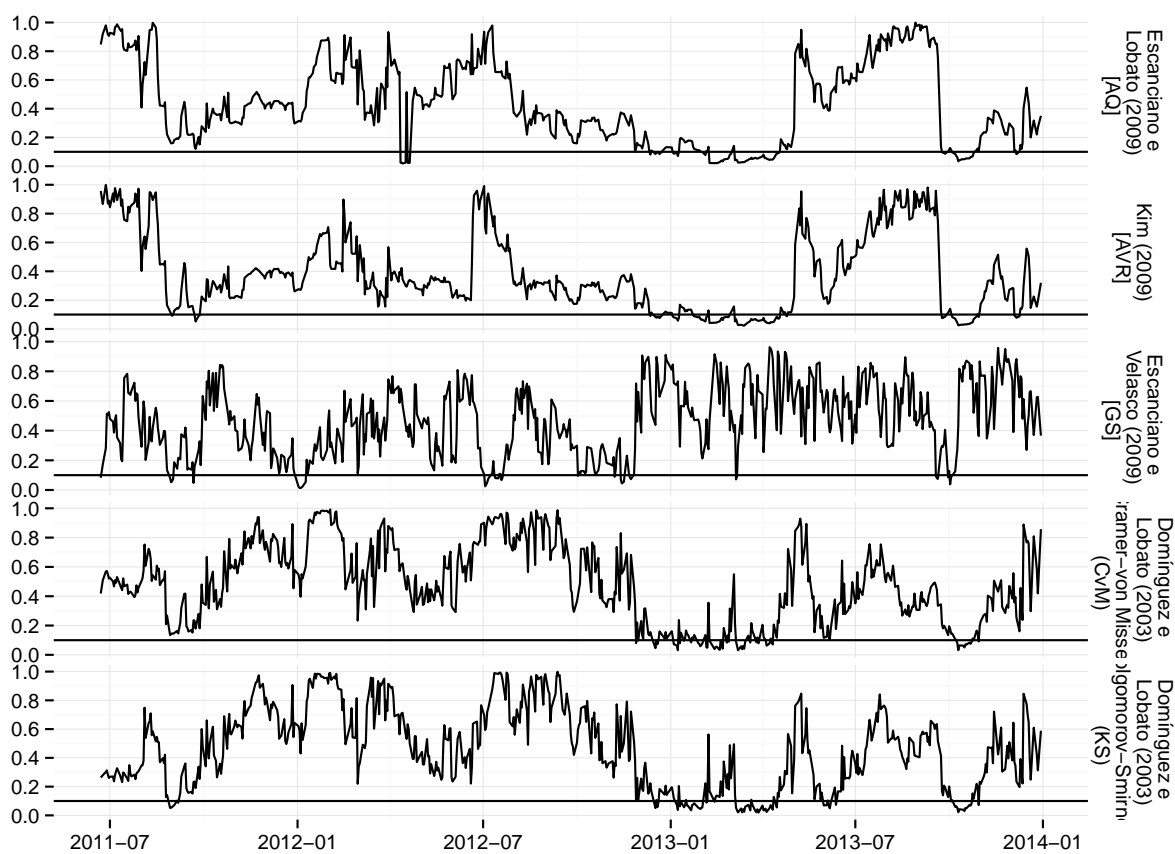

(b) ICF.2

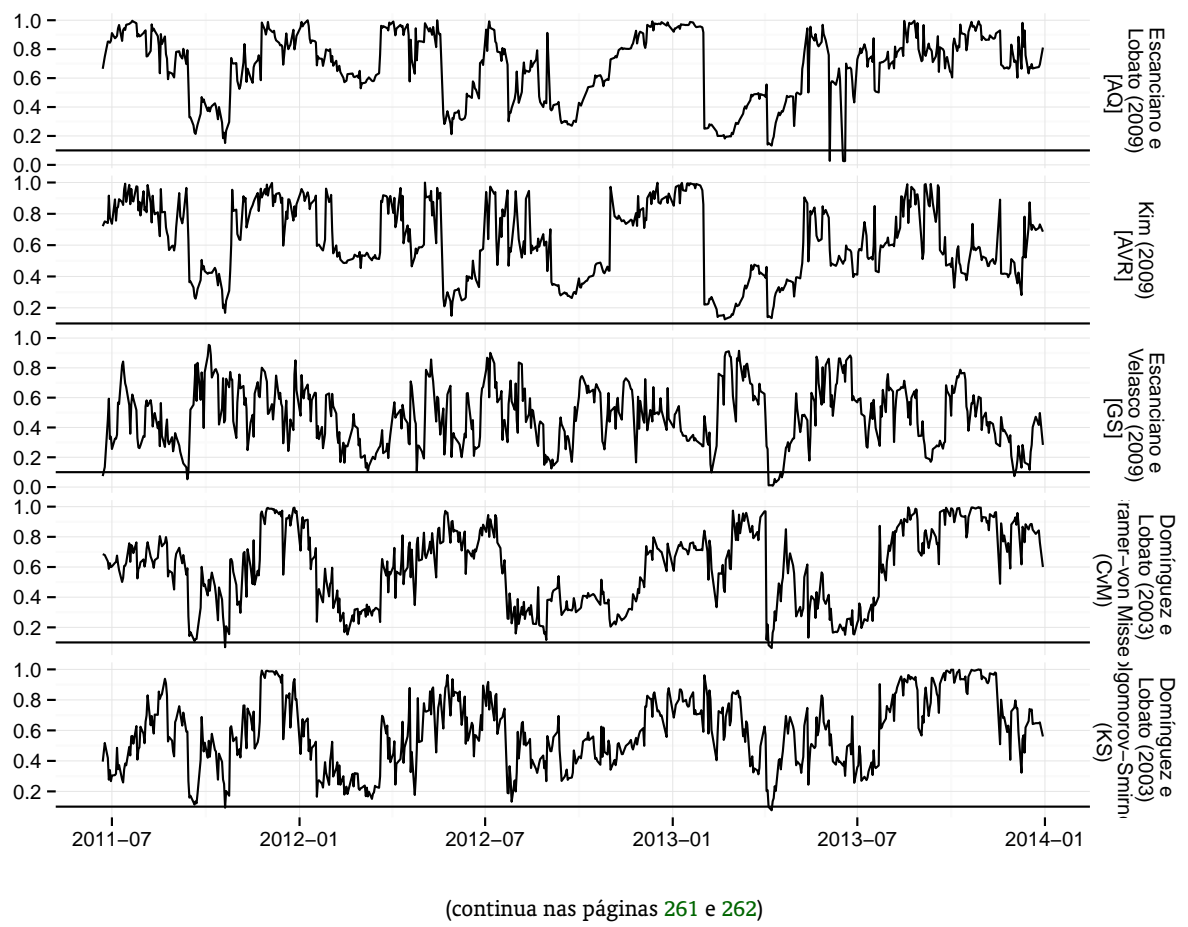


(c) CCM.2

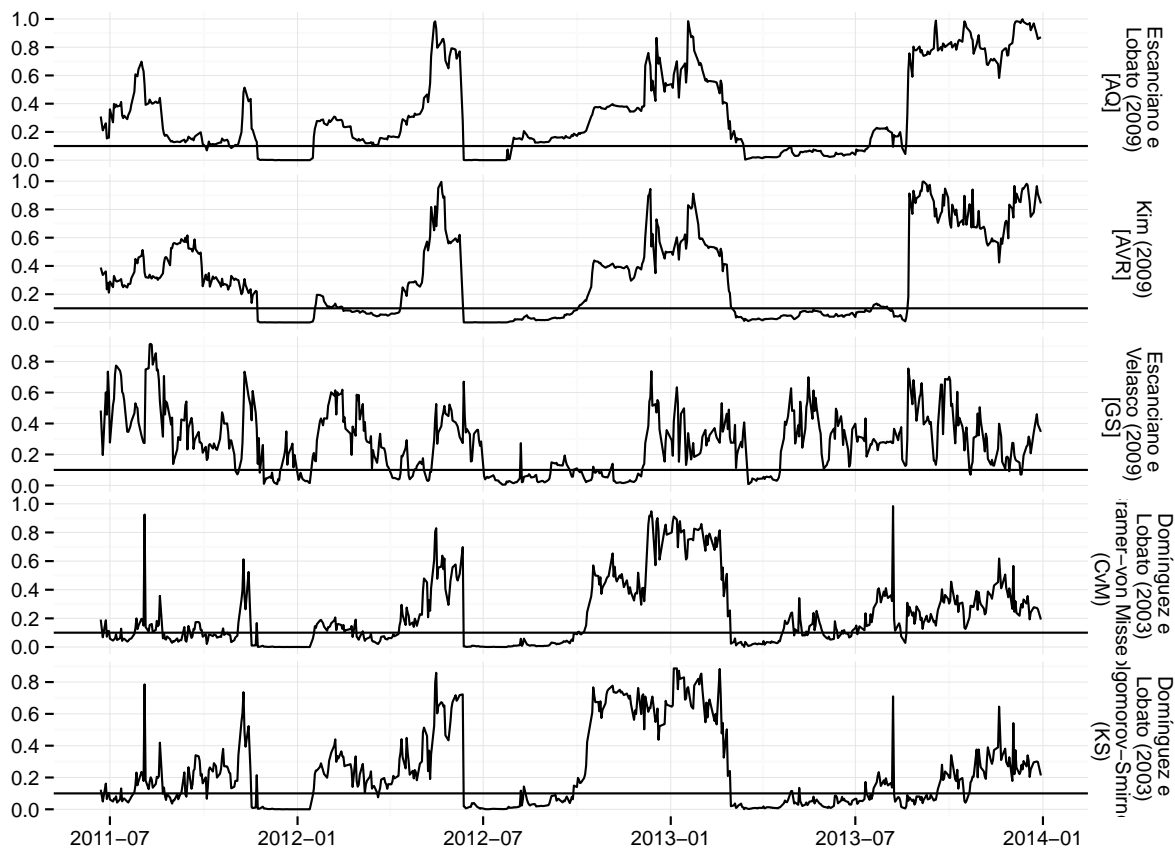

(d) ETH.2

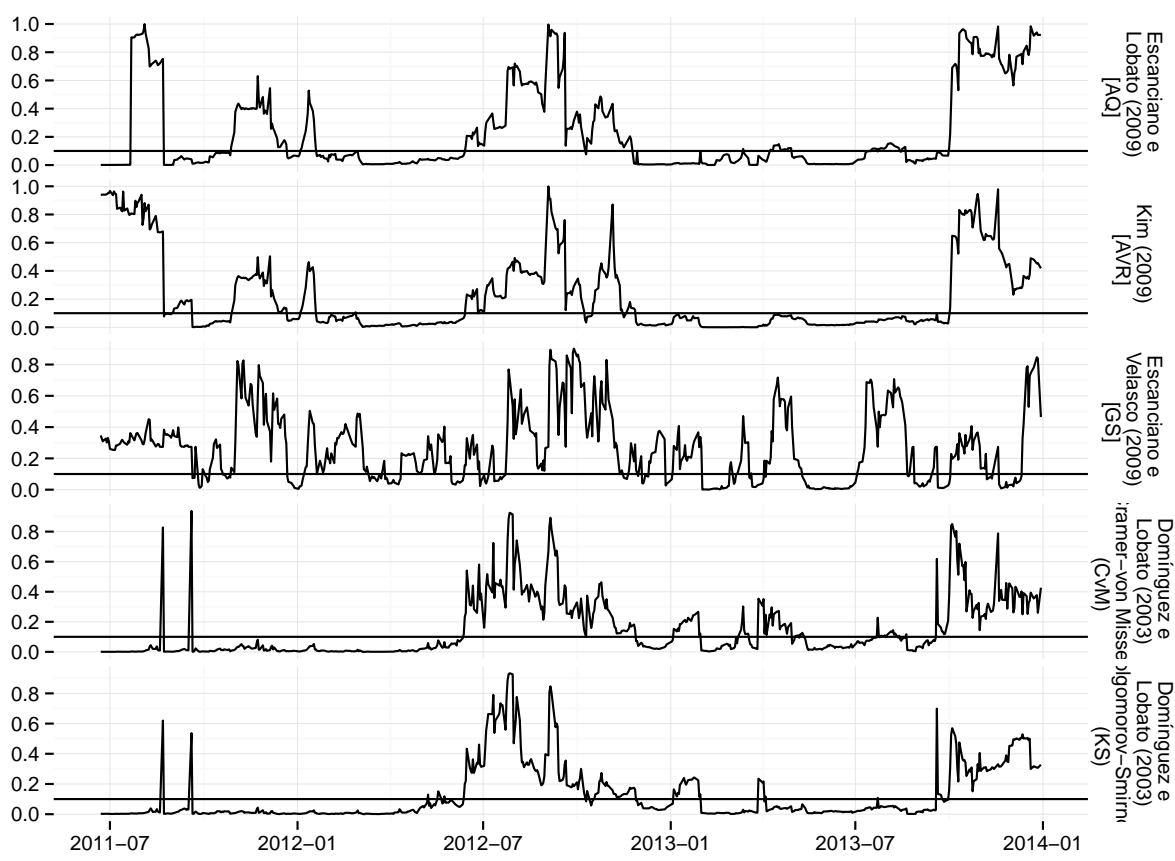




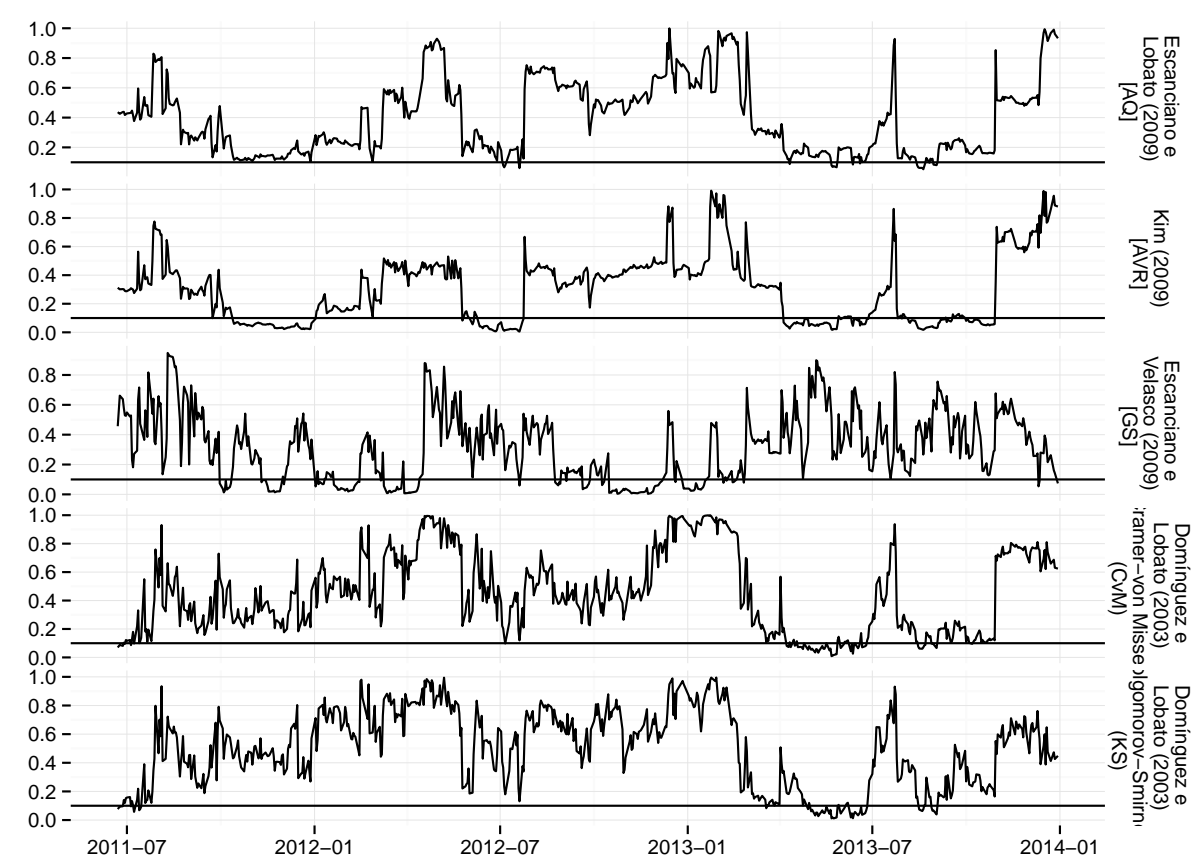

e a significância estatística a 10\% está tracejada na horizontal. Os períodos cujos valores- $p$ situam-se abaixo da linha tracejada indicam presença de predicabilidade dos retornos para a subamostra correspondente ao janelamento. Exemplificando a abordagem, o primeiro período de janelamento disposto na Figura 3 começa em 26 de setembro de 2000 e termina em 21 de fevereiro de 2001 . As estatísticas foram computadas para esse período e, então, move-se um período à frente, até a última subamostra que começou em 7 de agosto de 2013 e terminou em 30 de dezembro de 2013. Dessa forma, as estatísticas foram calculadas 3.184 vezes.

Pode-se observar na Figura 3 que, no mercado de café, falha-se na rejeição da hipótese de sequência de diferença martingal em longos períodos, e, portanto, evidencia-se eficiência informacional. Somente em períodos curtos rejeita-se a hipótese nula, ou seja, não coerentes com a hipótese de eficiência de mercado. Na mesma Figura 3, nota-se que o mercado de boi gordo apresenta de forma mais frequente períodos não condizentes com a hipótese de eficiência. Para esses mesmos mercados, mas no corte temporal mais recente, disposto na Figura 4, é possível inferir o inverso. O mercado de café apresenta maior frequência de desvios à sequência de diferença martingal. Ao contrário do que se espera de um mercado com funcionamento informacional, sugerem-se, portanto, comportamentos variáveis no tempo e não uma melhora contínua na eficiência informacional, o que provê suporte empírico à hipótese adaptativa de Lo $(2004,2005)$.

Os embargos à carne brasileira, as intervenções governamentais no mercado de café, além das mudanças conjunturais, alteraram a dinâmica dos preços e influenciaram a eficiência informacional. Exemplificando os períodos com rejeição à hipótese de eficiência de mercado, pode-se citar as incertezas geradas no período eleitoral de 2002, que repercutiram em desvalorização cambial e, consequentemente, nos mercados de café e boi gordo. A crise de 2008 refletiu para que ocorresse inversão do ciclo de alta das commodities. Além desses fatores conjunturais, o mercado de café passou por intervenções governamentais diretas: por Opções Públicas e Prêmio Equalizador Pago ao Produtor Rural (PEPRO) nos anos de 2003, 2007, 2009 e 2013. Para o mercado de boi gordo, ocorreram nesse período embargos à carne 
bovina brasileira pela União Europeia e Rússia, tanto em âmbito nacional como também restrito a alguns estados.

Os demais mercados - dispostos na Figura 4 - destacam-se com comportamentos de possível predição de seus retornos mais frequentes, em particular, no mercado de etanol. Essa evidência de predição em períodos de tempo e entre mercados está de acordo com a hipótese adaptativa de mercado proposta por Lo $(2004,2005)$, podendo ser creditada à terceira implicação da hipótese adaptativa de eficiência, isto é, as estratégias de investimentos aumentam e diminuem, obtendo boas performances em certos mercados e o contrário em outros. Diferentes características das commodities e de seus mercados, a qualidade das informações e incertezas sobre as condições econômicas são fatores potenciais que influenciam a eficiência dos mercados futuros agropecuários Garcia et al. (1988).

No mercado de etanol, os períodos de rejeição à eficiência ocorreram concomitantes às distorções ocasionadas pelo governo. É possível citar as alterações no padrão de competitividade desse combustível em relação à gasolina, devido às modificações no percentual adicionado de etanol, assim como a manutenção artificial do preço da gasolina. Em relação ao mercado de milho, este foi historicamente marcado por intervenções do governo via Política de Garantia de Preços Mínimos (PGPM). Nos anos safra 2010/2011 e 2013/2014, essas foram implementadas com o uso do Prêmio para Escoamento de Produto (PEP) e PEPRO. Destaca-se, também, que as condições edafoclimáticas desfavoráveis nos Estados Unidos em 2011 e 2012, seguidas da safra recorde norte-americana em 2013, tiveram impacto relevante no período. De modo oposto, no período analisado, as políticas governamentais não se fizeram presentes no mercado de soja com a intensidade que ocorreram nos mercados de milho e etanol, seja por execuções de instrumentos de PGPM, como no caso do milho, ou com as legislações sob o mercado de etanol. Apesar de ser contemplada nos Planos Agrícolas e Pecuários, a atuação do governo pode ser considerada como limitada, ao atuar com o Programa de Subvenção ao Prêmio do Seguro Rural.

Essas evidências contrastam com os resultados sobre mercados agropecuários no Brasil apresentados na Tabela 1, como, por exemplo: Alves et al. (2008); Arbex \& Carvalho (1999); Cruz \& Silveira (2007); Fraga \& Silva (2011); Menegario et al. (2014); Moraes et al. (2009). Tais estudos testam a eficiência dos mercados de forma estática, e percebe-se, com base nos resultados das Figuras 3 e 4, que a eficiência informacional dos mercados agropecuários brasileiros é variante no tempo. E depende das mudanças de comportamento dos agentes, do ambiente de mercado e das características das commodities.

A Tabela 4 apresenta os percentuais dos testes estatisticamente significativos a $10 \%$ nas subamostras referentes às Figuras 3 e 4, o que possibilita medir quantas vezes a hipótese de diferença martingal é rejeitada pelas estatísticas dos testes durante o período amostral. Um percentual elevado indica maior frequência do desvio da hipótese martingal, ou seja, um menor grau de eficiência informacional. E assim, permite classificar os contratos do mais eficiente ao menos eficiente.

Utilizando esses percentuais entre 2001 e 2013, pode-se inferir maior eficiência informacional no mercado de café comparado com o mercado de boi gordo (Painel A, Tabela 4). No entanto, o inverso ocorreu considerando período mais recente (2011-2013) no Painel B. Uma das possíveis explicações pode ser atribuída ao número de negócios e à diversificação dos agentes, conforme Figuras 1 e 2 . Enquanto no contrato de boi gordo houve uma elevação na quantidade de negócios, concomitante com a diversificação de agentes neste mercado, no de café ocorreu diminuição de contratos negociados e concentração de agentes.

Em período mais recente (Painel B, Tabela 4) pode-se inferir da média dos desvios à hipótese martigal o seguinte ranking de eficiência informacional: boi gordo, café, soja, milho e etanol. o mercado de milho apresentou elevado desvio à hipótese martingal, inferior apenas ao mercado de etanol. Isso aconteceu apesar da participação crescente dos investidores institucionais e de pessoas jurídicas não financeiras, concomitante com o aumento de liquidez e participação preponderante entre os ativos agropecuários e no número de contratos negociados recentemente. A concentração dos tipos de participantes e o baixo volume de negócios, característica do mercado futuro de etanol, podem ser uma das explicações para o maior percentual de rejeição da hipótese de diferença martingal e, portanto, a menor eficiência. Além disso, apesar do processo de desregulamentação das atividades vinculadas à agropecuária ressaltado 
Tabela 4. Percentuais das estatísticas Escanciano \& Lobato (2009a), Kim (2009), Escanciano \& Velasco (2006) e Domínguez \& Lobato (2003) significantes a 10\%.

\begin{tabular}{|c|c|c|c|c|c|c|}
\hline & \multicolumn{2}{|c|}{ Dependência linear } & \multicolumn{3}{|c|}{ Dependência não linear } & \multirow{2}{*}{$\begin{array}{l}\text { Dependências lineares } \\
\text { e não lineares (média) }\end{array}$} \\
\hline & $Q_{\tilde{p}}^{*}$ & $A V R^{*}$ & $D_{T}^{2}$ & $C v M$ & $K S$ & \\
\hline \multicolumn{7}{|c|}{ Painel A: Janelamento móvel de 21/6/2001-30/12/2013 } \\
\hline ICF.1 & 5,81 & 7,16 & 6,88 & 5,75 & 6,09 & 6,33 \\
\hline BGI.1 & 21,67 & 26,29 & 14,45 & 27,64 & 26,57 & 23,32 \\
\hline \multicolumn{7}{|c|}{ Painel B: Janelamento móvel de 22|6/2011-30|12|2013 } \\
\hline ICF.2 & 13,74 & 15,81 & 5,75 & 9,11 & 11,98 & 11,27 \\
\hline BGI.2 & 0,64 & 0 & 2,4 & 0,48 & 0,48 & 0,79 \\
\hline CCM.2 & 26,04 & 42,17 & 25,88 & 42,65 & 44,09 & 36,16 \\
\hline ETH.2 & 55,43 & 56,87 & 31,31 & 59,9 & 67,41 & 54,18 \\
\hline SFI.2 & 3,35 & 30,99 & 23,32 & 9,74 & 8,47 & 15,17 \\
\hline
\end{tabular}

Notas: ICF, BGI, CCM, ETH e SFI denotam os contratos de café, boi gordo, milho, etanol e soja, respectivamente. Os números 1 e 2 após os códigos dos contratos representam, respectivamente, os períodos amostrais (26 de setembro de 2000 a 30 de dezembro de 2013) e (28 de janeiro de 2011 a 30 de dezembro de 2013). Os testes sob dependências lineares referem-se a $Q_{\tilde{p}}^{*}$ e $A V R^{*} . Q_{\tilde{p}}^{*}$ denota o teste de Escanciano \& Lobato (2009a). $A V R^{*}$ denota o teste de Kim (2009). Os testes de dependências não lineares referem-se a $D_{T}^{2}, C v M$ e $K S . D_{T}^{2}$ denota o teste de Escanciano \& Velasco (2006), $C v M$ e $K S$ denotam os testes de Domínguez \& Lobato (2003), com base nas estatísticas Cramer-von Mises e Kolgomorov-Smirnov, respectivamente.

por Bacha (2012), há interferências governamentais que podem influenciar negativamente a eficiência informacional.

Podem-se inferir, portanto, importantes implicações aos agentes que utilizam informações de mercados futuros. Segundo Garcia et al. (1988) os agentes tomam decisões de produção, comercialização e estocagem sujeitas a informações completas contidas nos preços passados. Assim sendo, infere-se que na maior parte do tempo, no mercado de café e mais recentemente no de boi gordo, essas decisões podem resultar em alocação eficiente de seus recursos. De acordo com Frick \& Campos (1996), ao melhorar a eficiência de mercado, há melhoria no possível hedge adequado às necessidades dos agentes. No entanto, uma vez que os mercados de milho e etanol se desviam em proporção relativamente superior da hipótese de sequência de diferença martingal, e, por conseguinte, da eficiência informacional, os agentes desses mercados podem ter uma redução de seus excedentes econômicos, aumento dos custos informacionais e imprecisões nas decisões, conforme argumentos de Garcia et al. (2008) e Arbex \& Carvalho (1999).

As elevadas frequências de rejeição da hipótese de sequência de diferença martingal nos mercados futuros auxiliam na explicação da relutância ao uso dos mercados de derivativos como alternativa de proteção ao risco. Essa inferência encontra respaldo no argumento de Sabuhoro \& Larue (1997), devido a custos de transação adicionais ao hedge nos mercados não informacionalmente eficientes. $\mathrm{E}$ também na não otimalidade da taxa de hedge, pois, segundo Kroner \& Sultan (1993), pressupõem que os preços seguem um processo martingal.

A detecção de previsibilidade nesses ativos, mesmo que temporária, pode auxiliar na elaboração de estratégias de trading. Os resultados desta pesquisa são coerentes com os os argumentos de Timmermann \& Granger (2004) à previsibilidade, pois podem aparecer e desaparecer rapidamente. Assim, especuladores, administradores de fundos de investimentos e de pensão, citados por Marques et al. (2008), podem obter ganhos nesse ambiente em conformidade com a hipótese adaptativa de eficiência dos mercados futuros agropecuários na BM\&FBOVESPA. No entanto, deve-se ter cautela, pois a métrica proposta por Lesmond et al. (1999) sugere elevados custos de transação, em particular, nos mercados de etanol e da soja, conforme Tabela 2. 


\section{CONSIDERAÇÕES FINAIS}

As evidências consistentes com a hipótese adaptativa dos mercados justificam operações de hedge dinâmicas nessas commodities, bem como a gerência de carteiras de investimentos de forma ativa, uma vez que as predicabilidades e, por conseguinte, as oportunidades de ganhos surgem de tempos em tempos.

As elevadas rejeições à hipótese de diferença martingal encontram-se nos mercados em que as intervenções governamentais se fazem presentes: milho e etanol. Essas interferências dificultam o funcionamento informacional nos mercados futuros dessas commodities. Mesmo diante das adaptações dos agentes às mudanças nas condições dos mercados, os resultados desta pesquisa revelam a essencialidade de menor intervenção governamental, aliada às iniciativas da Bolsa em atrair e diversificar os agentes nesses mercados, bem como em elevar o volume negocial, como se evidenciou nos mercados de café e boi gordo. Mercados onde houve menores rejeições à hipótese martingal e maior eficiência informacional.

\section{REFERÊNCIAS BIBLIOGRÁFICAS}

Abitante, K. G. (2008). Co-integração entre os mercados spot e futuro: evidências dos mercados de boi gordo e soja. Revista de Economia e Sociologia Rural, 46(1), 75-96.

Alves, J. S., Duarte, G. S. \& Lima, R. C. (2008). Teste da eficiência do mercado futuro do álcool anidro no Brasil: Uma análise de co-integração. Revista Econômica do Nordeste, 39(1), 173-184.

Andrews, D. W. K. (1991). Heteroskedasticity and autocorrelation consistent covariance matrix estimation. Econometrica, 59(3), 817-858.

Arbex, M. A., \& Carvalho, V. (1999). Eficiência do mercado futuro de café brasileiro no período de 1992 a 1998. Revista de Economia e Sociologia Rural, 37(1), 97-113.

Bacha, C. J. C. (2012). Economia e política agrícola no Brasil (2ª ed.). São Paulo: Atlas.

Bressan, A. A., \& Leite, C. A. M. (2001). Eficiência do mercado futuro de café no Brasil. Reuna, 6(1), 11-32.

Broock, W. A., Scheinkman, J. A., Dechert, W. D. \& LeBaron, B. (1996). A test for independence based on the correlation dimension. Econometric Reviews, 15(3), 197-235.

Capitani, D. H. D., Mattos, F. L. \& Martines, J. G., Filho. (2012). Mensuração do risco de preços em diferentes mercados de commodities agrícolas no Brasil. In XII Encontro Brasileiro de Finanças, São Paulo.

Carter, C. A., \& Mohapatra, S. (2008). How reliable are hog futures as forecasts? American Journal of Agricultural Economics, 90(2), 367-378.

Charles, A., \& Darné, O. (2009). Variance-ratio tests of random walk: An overview. Journal of Economic Surveys, 23(3), 503-527.

Charles, A., Darné, O. \& Kim, J. H. (2011). Small sample properties of alternative tests for martingale difference hypothesis. Economics Letters, 110(3), 151-154.

Charles, A., Darné, O. \& Kim, J. H. (2012). Exchange-rate return predictability and the adaptive markets hypothesis: Evidence from major foreign exchange rates. Journal of International Money and Finance, 31(6), 16071626.

Chen, S.-S., Lee, C.-F. \& Shrestha, K. (2003). Futures hedge ratios: A review. The Quarterly Review of Economics and Finance, 43(3), 433-465.

Choi, I. (1999). Testing the random walk hypothesis for real exchange rates. Journal of Applied Econometrics, 14(3), 293-308.

Cont, R. (2001). Empirical properties of asset returns: Stylized facts and statistical issues. Quantitative Finance, 1(2), 223-236. 
Cruz, J. C., Jr, \& Silveira, R. L. F. (2007). Análise de eficiência, co-integração e exogeneidade nos mercados futuros de café na BM\&F, NYBoT e LIFFE. In XLV Congresso Brasileiro de Economia e Sociologia Rural, Rio Branco.

Domínguez, M. A., \& Lobato, I. N. (2003). Testing the martingale difference hypothesis. Econometric Reviews, 22(4), 351-377.

Doornik, J. A., \& Hansen, H. (2008). An omnibus test for univariate and multivariate normality. Oxford Bulletin of Economics and Statistics, 70, 927-939.

Dourado, G. A., \& Tabak, B. M. (2013). Teste da hipótese de mercados adaptativos para o Brasil (Trabalhos para discussão $\mathrm{N}^{0}$ 325). Brasília, DF: Banco Central do Brasil.

Escanciano, J. C., \& Lobato, I. N. (2009a). An automatic portmanteau test for serial correlation. Journal of Econometrics, 151(2), 140-149.

Escanciano, J. C., \& Lobato, I. N. (2009b). Testing the martingale hypothesis. In T. C. Mills \& K. Patterson (Eds.), Palgrave handbook of econometrics (Vol. 2: applied econometrics). New York: Palgrave Macmillan.

Escanciano, J. C., \& Velasco, C. (2006). Generalized spectral tests for the martingale difference hypothesis. Journal of Econometrics, 134(1), 151-185.

Fama, E. F. (1970). Efficient capital markets: A review of theory and empirical work. The Journal of Finance, 25(2), 383-417.

Fisher, T. J., \& Gallagher, C. M. (2012). New weighted portmanteau statistics for time series goodness of fit testing. Journal of the American Statistical Association, 107(498), 777-787.

Fraga, G. J., \& Silva, W. A., Neto. (2011). Eficiência no mercado futuro de commodity: Evidências empíricas. Revista Econômica do Nordeste, 42(1), 125-137.

Frick, O. O., \& Campos, R. B. M. (1996). Eficiência do mercado futuro de boi gordo. Resenha BMEF, 113.

Garcia, P., Hudson, M. A. \& Waller, M. L. (1988). The pricing efficiency of agricultural futures markets: An analysis of previous research results. Southern Journal of Agricultural Economics, 20(1), 119-130.

Garcia, P., \& Leuthold, R. M. (2004). A selected review of agricultural commodity futures and options markets. European Review of Agricultural Economics, 31(3), 235-272.

Garcia, P., Leuthold, R. M. \& Egelkraut, T. M. (2008). Issues and research opportunities in agricultural futures markets. In B. A. Goss (Ed.), Debt, risk and liquidity in futures markets. New York: Routledge.

Hakkio, C. (1986). Does the exchange rate follow a random walk? A Monte Carlo study of four tests for a random walk. Journal of International Money and Finance, 5(2), 221-229.

Hsu, P.-H., \& Kuan, C.-M. (2005). Reexamining the profitability of technical analysis with data snooping checks. Journal of Financial Econometrics, 3(4), 606-628.

Hussein, A. (2011). Market efficiency of the Ethiopia commodity exchange: The case of export coffee trading. Saarbrücken: VDM Verlag Dr. Müller.

Kim, J. H. (2009). Automatic variance ratio test under conditional heteroskedasticity. Finance Research Letters, 6(3), 179-185.

Kroner, K. F., \& Sultan, J. (1993). Time-varying distributions and dynamic hedging with foreign currency futures. The Journal of Financial and Quantitative Analysis, 28(4), 535-551.

Lesmond, D. A., Ogden, J. P. \& Trzcinka, C. A. (1999). A new estimate of transaction costs. Review of Financial Studies, 12(5), 1113-1141.

Lim, K.-P., \& Brooks, R. (2011). The evolution of stock market efficiency over time: A survey of the empirical literature. Journal of Economic Surveys, 25(1), 69-10.

Lim, K.-P., Luo, W. \& Kim, J.H. (2013). Are US stock index returns predictable? Evidence from automatic autocorrelation-based tests. Applied Economics, 45(8), 953-962. 
Lima, R. C., Góis, M. R. \& Ulises, C. (2007). Previsão de preços futuros de commodities agrícolas com diferenciações inteira e fracionária, e erros heteroscedásticos. Revista de Economia e Sociologia Rural, 45(3), 621-644.

Lo, A. W. (2004). The adaptive markets hypothesis: Market efficiency from an evolutionary perspective. The Journal of Portfolio Management, 30(5), 15-29.

Lo, A. W. (2005). Reconciling efficient markets with behavioral finance: The adaptive markets hypothesis. Journal of Investment Consulting, 7(5), 21-44.

Lo, A. W. (2012). Adaptive markets and the new world order. Financial Analysts Journal, 68(2), 18-29.

Lobato, I., Nankervis, J. C. \& Savin, N.E. (2001). Testing for autocorrelation using a modified Box-Pierce $Q$ test. International Economic Review, 42(1), 187-205.

Marques, P. V., Mello, P. C. \& Martines, J. G., Filho. (2008). Mercados futuros agropecuários: Exemplos e aplicações para o mercado brasileiro. Rio de Janeiro: Elsevier.

Menegario, A. H., Paiva, A. R. N., Souza, W. A. R., Martines, J. G., Filho \& Marques, P. V. (2014). Eficiência comparativa dos mercados futuros no Brasil e exterior para a comercialização da safra de café brasileira. Pesquisa $E$ Debate, 24(1), 25-49.

Moraes, A. S., Lima, R. C. \& de Souza Melo, A. (2009). Análise da eficiência do mercado futuro brasileiro de boi gordo usando co-integração. Revista de Economia e Sociologia Rural, 47(3), 601-614.

Park, C.-H., \& Irwin, S. H. (2007). What do we know about the profitability of technical analysis? Journal of Economic Surveys, 21(4), 786-826.

Righi, M. B., \& Ceretta, P. S. (2011). Previsibilidade e eficiência no mercado agrícola. Ciência Rural, 41(10), 18441850.

Saboya, L. V., \& Bacchi, M. R.P. (1999). Uma proposta metodológica para análise da eficiência na formação de preços de contratos futuros. In Congresso Brasileiro de Economia e Sociologia Rural, Foz do Iguaçu.

Sabuhoro, J. B., \& Larue, B. (1997). The market efficiency hypothesis: The case of coffee and cocoa futures. Agricultural Economics, 16(3), 171-184.

Samuelson, P. A. (1965). Proof that properly anticipated prices fluctuate randomly. Industrial Management Review, 5(2), 41-49.

Timmermann, A., \& Granger, C. W. J. (2004). Efficient market hypothesis and forecasting. International Journal of Forecasting, 20(1), 15-27.

Torres, R., Bonomo, M. \& Fernandes, C. (2002). A aleatoriedade do passeio na Bovespa: Testando a eficiência do mercado acionário brasileiro. Revista Brasileira de Economia, 56(2), 199-247.

Wang, H. H., \& Ke, B. (2005). Efficiency tests of agricultural commodity futures markets in China. Australian Journal of Agricultural and Resource Economics, 49(2), 125-141.

White, H. (2000). A reality check for data snooping. Econometrica, 68(5), 1097-1126. 